\title{
COMPUTER SIMULATION OF THE HYDRODYNAMICS OF A TWO-DIMENSIONAL GAS-FLUIDIZED BED
}

\author{
J. A. M. Kuipers, K. J. van Duin, F. P. H. van Beckum and W. P. M. van SwaAit \\ Department of Chemical Engineering, Twente University of Technology, P.O. Box 217 , \\ 7500 AE Enschede, The Netherlands
}

\author{
(Received 19 December 1991; final revision received 2 November 1992; received for publication
}

9 December 1992)

\begin{abstract}
A first principles model of a gas-fluidized bed has been applied to calculate the hydrodynamics of a two-dimensional (2-D) bed with an orifice in the middle of a porous plate distributor. The advanced hydrodynamic model is based on a two fluid model approach in which both phases are considered to be continuous and fully interpenetrating. Conservation equations for mass, momentum and thermal energy have been solved numerically by a finite difference technique on a mini-computer. Our computer model calculates the porosity, the pressure, the fluidum phase temperature, the solid phase temperature and the velocity fields of both phases in 2-D Cartesian or axisymmetrical cylindrical coordinates. The new feature of the present model is the incorporation of Newtonian behaviour in the gas and solid phases. Our preliminary calculations indicate that the sensitivity of the computed bubble size with respect to the bed rheology (i.e. the solid phase viscosity) is quite small. However the bubble shape appears to be much more sensitive to the bed rheology. Results of the calculations have been compared with data obtained from an experimental cold-flow model (height: $1000 \mathrm{~mm}$, width: $570 \mathrm{~mm}$, depth: $15 \mathrm{~mm}$ ).
\end{abstract}

\section{INTRODUCTION}

The motion of a system of solid particles suspended in a Newtonian gas or liquid can, at least in principle, be completely described by the Navier-Stokes equations for the fluid (i.e. the gas or the liquid) and the Newtonian equations of motion for each suspended solid particle. Specification of the proper initial and boundary conditions would enable determination of the mechanics of fluidized beds. However, fluidized beds contain a very large number of closely spaced solid particles and consequently a very large number of governing equations have to be solved when this theoretical approach is followed. Even with the present day supercomputing capabilities, it is not feasible to solve these equations and therefore a drastic reduction of the number of governing equations must be made. Such a reduction is possible through the introduction of a continuum mathematical description of the fluidized system. In fact, a similar approach is used, in fluid mechanics, for the derivation of the Navier-Stokes equations on the basis of molecular theory.

There is extensive literature dealing with the derivation of continuum equations for multiphase systems and a number of continuum models have been proposed (Anderson and Jackson, 1967; Ishii, 1975; Pritchett et al., 1978). In the so-called "two fluid model" both phases are considered to be continuous and fully interpenetrating. Both phases are described in terms of separate conservation equations with appropriate interaction terms representing the coupling between the phases. Fluid phase properties and the physical characteristics of the solid particles, such as the shape and size are included in the continuum representation. The derivation of the continuum equations is usually based on spatial averaging techniques. The point-hydrodynamical variables, describing processes on the scale of particle size are replaced by local averaged variables which describe these processes on a scale which is large compared to the particle size but small compared to the size of the macroscopic system of interest. As a result of the averaging procedure, the local averaged variables are defined at every point of the macroscopic system which is in contrast to the point-hydrodynamical variables which are only defined at locations occupied by the relevant phase. As a consequence of the spatial averaging, the theoretical description is based on a relatively small number of partial differential equations which reflect the principles of conservation of mass, momentum and thermal energy for both phases.

\section{MATHEMatical MOdeL}

These equations employed in the theoretical model can be seen as a generalization of the Navier-Stokes equations for two interacting continua. Two sets of conservation equations are used, governing the balance of mass, momentum and energy in each phase. 
Table 1. Two fluid model conservation equations in vector form

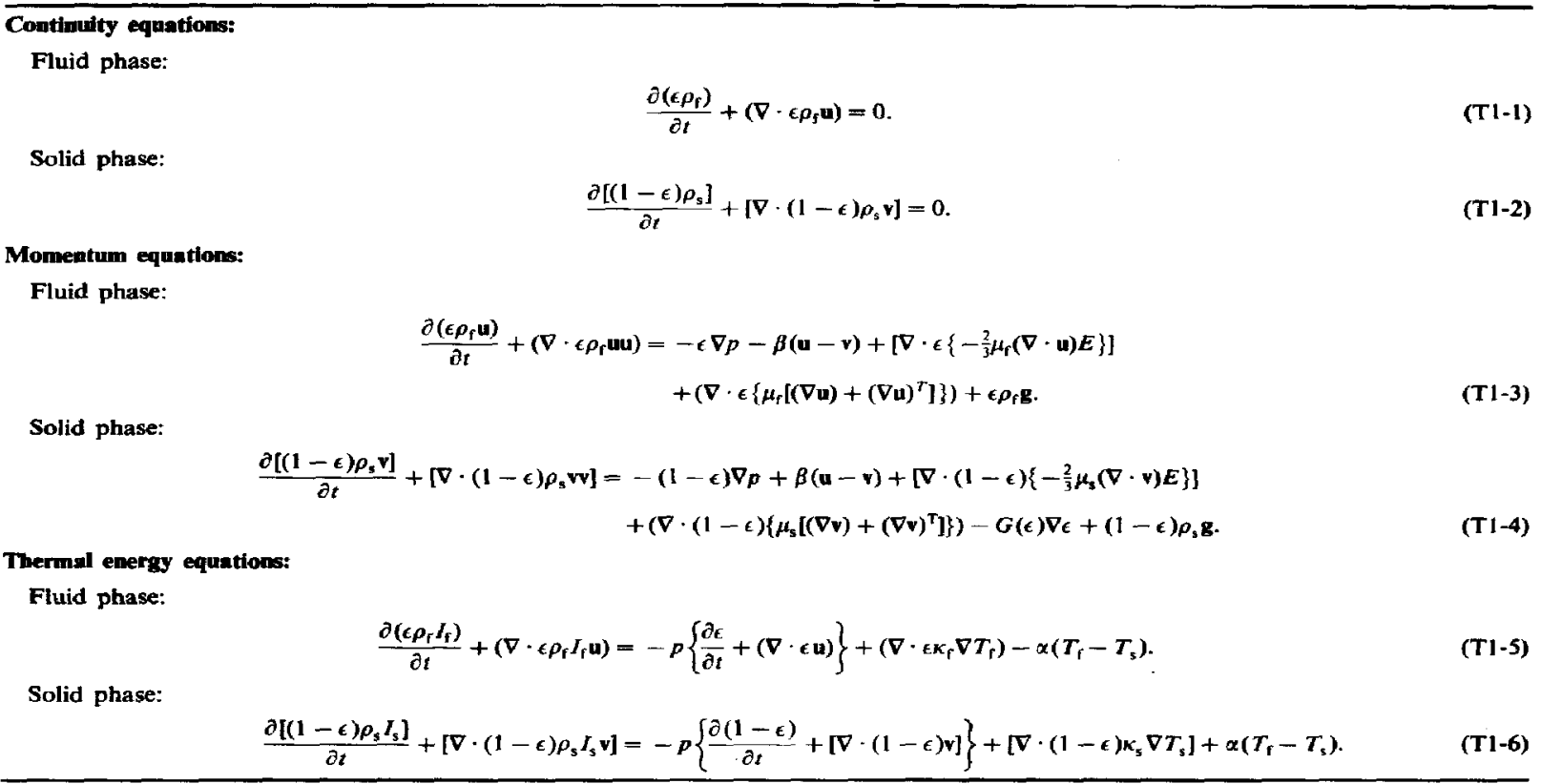

Table 1 shows the mass, momentum and thermal energy equations in vector form. For the purpose of solution of the balance equations the basic variables must be specified. For the present study the porosity $\epsilon$, the pressure $p$, the fluid phase temperature $T_{\mathrm{f}}$, the solid phase temperature $T_{s}$, the fluid phase velocity vector $\bar{u}$ and the solid phase velocity vector $\bar{v}$ have been chosen as the basic variables. For closure of the set of balance equations, specification of the constitutive relations is required. This means that all other variables in the balance equations must be specified in terms of the basic variables $\epsilon, p, T_{\mathrm{f}}, T_{\mathrm{s}}, \bar{u}$ and $\bar{v}$. Through the incorporation of the constitutive equations the necessary empirical information is introduced in the present thcorctical model of gas-fluidized beds. The constitutive equations have been listed in Table 2 .

\subsection{Initial and boundary conditions}

In order to obtain a unique solution to the system of partial differential equations it is necessary to specify the initial and the boundary conditions in terms of the basic variables. Because the detailed initial and boundary conditions are problem dependent only a few general remarks will be presented in this section.

2.1.1. Initial conditions. Throughout the domain of interest the local numerical values of all the basic variables must be specified. Among the many possible initial conditions only the minimum fluidization condition was considered in the present study. Usually a freeboard the same size as the initial bed height was provided to allow for bed expansion.

2.1.2. Boundary conditions. It is assumed that the domain of interest is bounded by walls. The wall type determines which houndary condition has to be prescribed at that particular wall. Several wall types have been included in the theoretical formulation such as

$$
\begin{aligned}
& \text {-free-slip rigid walls } \\
& \text { _no-slip rigid walls } \\
& \text {-prescribed inflow or outflow walls } \\
& \text {-continuative outflow walls }
\end{aligned}
$$

for the hydrodynamic equations and

-adiabatic walls

-prescribed temperature walls

-prescribed heat flux walls

for the thermal energy equations. As an option spatial and temporal variation of the boundary conditions has also been incorporated in the present model.

\section{COMPARISON WITH PREVIOUS WORK}

Gidaspow (1986) has recently reviewed three hydrodynamic models of fluidization for which numerical solutions have been obtained. Hydrodynamic models of fluidization use the principles of mass, momentum and energy conservation and have been developed by the Systems, Science and Software 
Fluid phase density $\rho_{\mathrm{r}}$ and solid phase density $\rho_{s}$ :

$$
\begin{gathered}
\rho_{\mathrm{r}}=\frac{M_{\mathrm{r} p}}{R T_{\mathrm{r}}} \\
\rho_{\mathrm{s}}=\rho_{\mathrm{s}, 0}
\end{gathered}
$$

Interphase momentum transfor coefficient $\beta$ :

For $\epsilon \leqslant 0.8$ :

$$
\beta=150 \frac{(1-\epsilon)^{2}}{\epsilon} \frac{\mu_{f}}{\left(\phi_{s} d_{p}\right)^{2}}+1.75(1-\epsilon) \frac{\rho_{f}}{\left(\phi_{g} d_{p}\right)}|u-v|
$$

For $\epsilon>0.8$

$$
\beta=\frac{3}{4} C_{\mathrm{d}} \frac{\epsilon(1-\epsilon)}{\left(\phi_{\mathrm{s}} d_{\mathrm{p}}\right)} \rho_{\mathrm{f}}|\mathbf{u}-\mathbf{v}| f(\epsilon)
$$

where

$$
f(\epsilon)=\epsilon^{-2.65}
$$

and

$$
\begin{array}{ll}
C_{\mathrm{d}}=\frac{24}{\operatorname{Re}_{\mathrm{p}}}\left[1+0.15\left(\mathrm{Re}_{\mathrm{p}}\right)^{0.687}\right], & \operatorname{Re}_{\mathrm{p}}<1000, \\
C_{\mathrm{d}}=0.44, & \operatorname{Re}_{\mathrm{p}} \geqslant 1000,
\end{array}
$$

where

$$
\operatorname{Re}_{\mathrm{p}}=\frac{\epsilon \rho_{\mathrm{f}}|\mathbf{u}-\mathbf{v}| d_{\mathrm{p}}}{\mu_{\mathrm{f}}}
$$

Fluid phase viscosity $\mu_{\mathrm{r}}$ and solid phase viscosity $\mu_{3}$ :

$$
\begin{aligned}
& \mu_{\mathrm{f}}=\mu_{\mathrm{r}, \mathrm{o}}, \\
& \mu_{\mathrm{s}}=\mu_{\mathrm{s}, \mathrm{o}},
\end{aligned}
$$

Solid phase elastic modulus $G(\epsilon)$ :

$$
G(\epsilon)=-1.0\{\exp [100(0.45-\epsilon)]\}
$$

Fluid phase internal energy $I_{f}$ and solid phase internal energy $I_{s}$ :

$$
\begin{aligned}
& \mathrm{d} I_{\mathrm{f}}=C_{\mathrm{p}, \mathrm{f}} \mathrm{d} T_{\mathrm{f}}, \\
& \mathrm{d} I_{\mathrm{s}}=C_{\mathrm{p}, \mathrm{s}} \mathrm{d} T_{\mathrm{s}} .
\end{aligned}
$$

Fluid phase thermal conductivity $\kappa_{\mathrm{f}}$ and solid phase thermal conductivity $\kappa_{\mathrm{s}}$

$$
\kappa_{s}=\frac{1}{\sqrt{(1-\epsilon)}}\{\omega A+(1-\omega) \Gamma\} \kappa_{\mathrm{r}, \mathrm{o}}
$$

where

and

$$
\Gamma=\frac{2}{\left(1-\frac{B}{A}\right)}\left\{\frac{(A-1)}{\left(1-\frac{B}{A}\right)^{2}} \frac{B}{A} \ln \left(\frac{A}{B}\right)-\frac{(B-1)}{\left(1-\frac{B}{A}\right)}-\frac{1}{2}(B+1)\right\}
$$

$$
\begin{gathered}
B=1.25\left(\frac{(1-\epsilon)}{c}\right)^{10 / 9}, \\
A=\frac{\kappa_{2,0}}{\kappa_{1,0}}, \\
\omega=7.26 \times 10^{-3} .
\end{gathered}
$$

Interphase heat transfer coefficient $\alpha$ :

$$
x=\frac{6(1-\epsilon)}{d_{p}} \alpha_{p}
$$

where

$$
N u_{p}=\frac{\alpha_{p} d_{p}}{\kappa_{r, o}}=\left(7-10 \epsilon+5 \epsilon^{2}\right)\left[t+0.7\left(\operatorname{Re}_{p}\right)^{0.2}(\operatorname{Pr})^{1 / 3}\right]+\left(1.33-2.40 \epsilon+1.20 \epsilon^{2}\right)\left(\operatorname{Re}_{p}\right)^{0.7}(\operatorname{Pr})^{1,3}
$$

and

$$
\operatorname{Pr}=\frac{C_{p, r} \mu_{\mathrm{r}}}{\kappa_{\mathrm{f}, \mathrm{o}}} .
$$

Group (Pritchett et al., 1978; Schneyer et al., 1981; computer code: CHEMFLUB), the JAYCOR group (Klein and Scharf,, 1982; Scharff et al., 1982; computer code: FLAG) and the IIT group (Gidaspow and Ettehadieh, 1983; Ettehadieh et al., 1984;
Syamlal and Gidaspow, 1985; computer code: K-FIX).

Contrary to the present computer code, in the CHEMFLUB code the gas inertial terms have been neglected because of the relative low density of gases 
and local thermodynamic equilibrium has been assumed because of the high volumetric interphase heat transfer coefficients prevailing in dense gas-fluidized beds. A modification of Darcy's law for flow in porous media, to account for the movement of the solid particles, has been employed in the CHEMFLUB code instead of the gas phase momentum equation. However, the gas inertial terms become important for high-speed jets entering fluidized beds and also become impurtant at elevated pressures which makes the unconditional neglect of the gas inertia doubtful from a physical viewpoint.

The K-FIX code, developed originally by Rivard and Torrey (1977) for gas-liquid two phase flow, has been adapted by Gidaspow and Ettehadieh (1983) and Ettehadieh et al. (1984) to gas-solid two-phase flow. In the modified K-FIX code, the viscous interaction terms for both phases have been neglected: both phases are considered to constitute an ideal (inviscid) continuum. For the gas phase this assumption can be justified but in general the solid phase cannot be considered as an ideal (inviscid) continuum. The present model incorporates, as a first approximation, Newtonian behaviour for both phases although it is recognized that this rather simple rheological model of fluidized suspensions is not consistent with all available experimental data (Gabor, 1972). The neglect of the viscous interaction terms is attractive from a computational viewpoint, as experienced by the developers of the K-FIX code (Rivard and Torrey, 1979), but the a priori deletion of these terms by Gidaspow (1986) in the modified $\mathrm{K}-\mathrm{FIX}$ code seems doubtful in view of the rather high apparent bed viscosities measured in dense fluidized beds. Similar to the present model separate thermal energy equations have been incorporated in the (modified) K-FIX code allowing for the computation of unequal temperature fields of the fluid (gas) phase and the solid phase.

The conventional multiphase approach in which the void fraction is used as a dependent variable was not adopted by the JAYCOR group in developing their FLAG code. This code solves the hydrodynamic equations for a single "representative" particle and calculates the void fraction distribution from the number of representative particles in a given unit cell. Their momentum equation for the particles is simply a balance between particle momentum, gravity and fluid particle drag. Their approach in modelling dense fluidized beds is in fact a generalization of the "dusty model" of Rudinger and Chang (1964). In the gas phase momentum equation employed in the FLAG code both the inertial and viscous momentum transport terms have been retained. Similar to the present computer code and the K-FIX code, the FLAG code employs two separate thermal energy equations. Computational experience with the FLAG code (Henline et al., 1981) has shown that in some cases, even in cold-flow simulations, severe numerical stability problems arose, nccessitating the termination of the calculations at fractions of $1 \mathrm{~s}$ real time.

\section{NUMERICAL SOLUTION}

The set of conservation equations, supplemented with the constitutive equations and the initial and boundary conditions cannot be solved analytically and therefore a numerical method must be used to obtain an approximate solution. Stewart and Wendroff (1984) have recently reviewed the state of the art with respect to the numerical modelling of multiphase flow problems. These authors discuss the available numerical methods and give guiding principles for selecting the appropriate one to a particular problem.

The numerical method used in the present investigation is based on a finite difference technique developed by Harlow and Amsden at the Los Alamos Scientific Laboratory (see Harlow and Amsden, 1974, 1975). This semi-implicit numerical method can be considered as an extension of the ICE-method of Harlow and Amsden (1971) to two-phase flow calculations. Due to the implicitness incorporated in the ICE-method the sonic time step limitation, usually encountered in explicit finite differencing techniques, is removed. A brief account of the numerical techique and the modifications made to enhance the computer solution will be given below. In the present study the numerical solution method will be restricted to perform transient 2-D calculations in a Cartesian or axisymmetrical geometry, however, it must be remembered that the present " $2-D$ " technique can readily be extended to a full 3-D numerical method. The outline of the numerical method will be given for the axisymmetrical geometry only.

\subsection{Representation of the flow domain}

The domain of interest is represented by a number of fixed Eulerian cells through which the fluid-solid dispersion moves. Depending on the problem and the required numerical resolution the total number of computational cells varied between 1000 and 5000 in the numerical computations.

The cells are labelled by indices $i$ and $j$, located at their centres (see Fig. 1). The scalar variables (porosity, pressure and temperature) are defined at the cell centres. The radial velocity components $u_{\mathrm{r}}$ and $v_{r}$ and the axial velocity components $u_{z}$ and $v_{z}$ are defined at the cell faces as indicated in Fig. 1. 


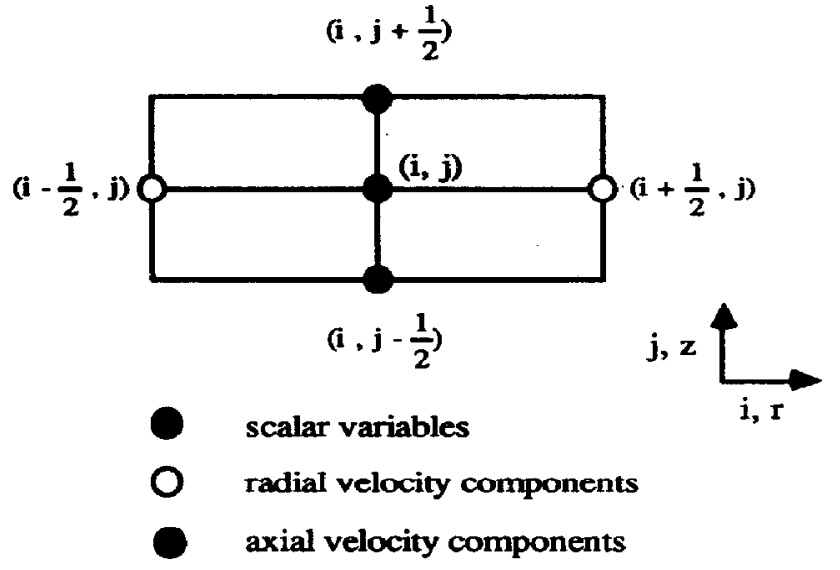

Fig. 1. A typical computational cell and the centring of the basic variables.

\subsection{Finite difference approximation}

4.2.1. Discretization of the time derivative. Partial derivative in time are replaced by a simple first-order approximation as follows:

$$
\left.\frac{\partial}{\partial t}(\Theta)\right|_{r, z} ^{t+\delta t}=\frac{\Theta(r, z, t+\delta t)-\Theta(r, z, t)}{\delta t}+O(\delta t)
$$

or

$$
\left.\frac{\partial}{\partial t}(\Theta)\right|_{r, z} ^{n+1}=\frac{\Theta(r, z)^{n+1}-\Theta(r, z)^{n}}{\delta t}+O(\delta t),
$$

where $n+1$ and $n$ represent the new and old time levels, respectively, and $\Theta$ represents the mass, momentum or thermal energy density.

4.2.2. Discretization of the convective transport terms. For the discretization of the convective transport terms in the mass, momentum and thermal energy conservation equations the upwind discretization technique has been used. Upwind finite differencing results in a first-order spatial truncation error. Although the central finite difference approximation results in a second-order spatial truncation error it is usually not employed in two-phase flow numerical computations because of the resulting numerical instability. Due to the upwind finite differencing of the convective transport terms some numerical or "false" diffusion occurs in practical calculations.

4.2.3. Discretization of the conductive transport terms. For the discretization of the viscous transport terms in the momentum equations and the conductive transport terms in the thermal energy equations standard central finite difference approximation with second-order spatial truncation errors have been used.
4.2.4. Discretization of the pressure and porosity gradient in the momentum equations. The pressure and porosity gradient in the momentum equations are finite differenced with standard central finite difference approximations as follows:

$$
\begin{aligned}
& \left.\frac{\partial p}{\partial r}\right|_{i+1 / 2, j} ^{n+1}=\frac{p_{i+1, j}^{n+1}-p_{i, j}^{n+1}}{\delta r}+O\left(\delta r^{2}\right), \\
& \left.\frac{\partial p}{\partial z}\right|_{i, j+1 / 2} ^{n+1}=\frac{p_{i, j+1}^{n+1}-p_{i, j}^{n+1}}{\delta z}+O\left(\delta z^{2}\right) .
\end{aligned}
$$

4.2.5. Discretization of the continuity equations. For both continuity equations a fully implicit discretization has been used:

Fluid phase:

$$
\begin{aligned}
& \left(\epsilon \rho_{\mathrm{f}}\right)_{i, j}^{n+1}-\left(\epsilon \rho_{\mathrm{f}}\right)_{i, j}^{n}+\frac{\delta t}{\delta r} \frac{1}{r_{i}}\left\{\left\langle r \epsilon \rho_{\mathrm{f}} u_{\mathrm{r}}\right\rangle_{i+1 / 2, j}^{n+1}\right. \\
& \left.-\left\langle r \epsilon \rho_{\mathrm{f}} u_{\mathrm{r}}\right\rangle_{i-1 / 2, j}^{n+1}\right\}+\frac{\delta t}{\delta z}\left\{\left\langle\epsilon \rho_{\mathrm{f}} u_{z}\right\rangle_{i, j+1 / 2}^{n+1}\right. \\
& \left.-\left\langle\epsilon \rho_{\mathrm{f}} u_{z}\right\rangle_{i, j-1 / 2}^{n+1}\right\}=0 .
\end{aligned}
$$

Solid phase:

$$
\begin{aligned}
& {\left[(1-\epsilon) \rho_{\mathrm{s}}\right]_{i, j}^{n+1}-\left[(1-\epsilon) \rho_{\mathrm{s}}\right]_{i, j}^{n}+\frac{\delta t}{\delta r} \frac{1}{r_{i}}} \\
& \left\{\left\langle r(1-\epsilon) \rho_{\mathrm{s}} v_{\mathrm{r}}\right\rangle_{i+1 / 2, j}^{n+1}\right. \\
& \left.-\left\langle r(1-\epsilon) \rho_{\mathrm{s}} v_{\mathrm{r}}\right\rangle_{i=1 / 2, j}^{n+1}\right\} \\
& +\frac{\delta t}{\delta z}\left\{\left\langle(1-\epsilon) \rho_{\mathrm{s}} v_{z}\right\rangle_{i, j+1 / 2}^{n+1}\right. \\
& \left.-\left\langle(1-\epsilon) \rho_{\mathrm{s}} v_{\mathrm{z}}\right\rangle_{i, j-1 / 2}^{n+1}\right\}=0 .
\end{aligned}
$$

The brackets in equations (3a) and (3b) denote the upwind finite differencing of the mass convection terms, for example:

$$
\begin{gathered}
\left\langle r(1-\epsilon) \rho_{\mathrm{s}} v_{\mathrm{r}}\right\rangle_{i+1 / 2, j}^{n+1}=\left(r v_{\mathrm{r}}\right)_{i+1 / 2, j}^{n+1}\left[(1-\epsilon) \rho_{\mathrm{s}}\right]_{i, j}^{n+1} \\
\text { if }\left(v_{\mathrm{r}}\right)_{i+1,2, j}^{n+1}>0 \\
\left\langle r(1-\epsilon) \rho_{\mathrm{s}} v_{z}\right\rangle_{i+1 / 2, j}^{n+1}=\left(r v_{\mathrm{r}}\right)_{i+1 / 2, j}^{n+1}\left[(1-\epsilon) \rho_{\mathrm{s}}\right]_{i+1, j}^{n+1} \\
\text { if }\left(v_{\mathrm{r}}\right)_{i+1 / 2, j}^{n+1}<0
\end{gathered}
$$

and

$$
\begin{gathered}
\left\langle(1-\epsilon) \rho_{\mathrm{s}} v_{z}\right\rangle_{i, j+1_{i}}^{n+1}=\left(v_{z}\right)_{i, j+1 / 2}^{n+1}\left[(1-\epsilon) \rho_{\mathrm{s}}\right]_{i, j}^{n+1} \\
\text { if }\left(v_{z}\right)_{i, j+1 / 2}^{n+1}>0 \\
\left\langle(1-\epsilon) \rho_{\mathrm{s}} v_{z}\right\rangle_{i, j+1 / 2}^{n+1}=\left(v_{z}\right)_{i, j+1 / 2}^{n+1}\left[(1-\epsilon) \rho_{\mathrm{s}}\right]_{i, j+1}^{n+1} \\
\text { if }\left(v_{z}\right)_{i, j+1 / 2}^{n+1}<0 .
\end{gathered}
$$

4.2.6. Discretization of the momentum equations. For the discretization of the momentum equations a mixed explicit-implicit technique has been used. Terms associated with the fluid pressurc, 
solid pressure and interphase momentum transfer have been treated implicitly whereas all other terms have been treated explicitly.

Fluid phase $r$-momentum:

$$
\begin{aligned}
\left(\epsilon \rho_{\mathrm{f}} u_{r}\right)_{i+1 / 2, j}^{n+1}= & A_{i+1 / 2, j}^{n}+\epsilon_{i+1 / 2, j}^{n+1} \frac{\delta t}{\delta r} \\
& \times\left(p_{i, j}^{n+1}-p_{i+1, j}^{n+1}\right) \\
& -K_{i+1 / 2, j}^{n}\left(u_{\mathrm{r}}-v_{\mathrm{r}}\right)_{i+1 / 2, j}^{n+1}
\end{aligned}
$$

Fluid phase $z$-momentum:

$$
\begin{aligned}
\left(\epsilon \rho_{\mathrm{r}} u_{z}\right)_{i, j+1 / 2}^{n+1}= & B_{i, j+1 / 2}^{n}+\epsilon_{i, j+1 / 2}^{n+1} \frac{\delta t}{\delta z} \\
& \times\left(p_{i, j}^{n+1}-p_{i, j+1}^{n+1}\right) \\
& -K_{i, j+1 / 2}^{n}\left(u_{z}-v_{z}\right)_{i, j+1 / 2}^{n+1}
\end{aligned}
$$

Solid phase $r$-momentum:

$$
\begin{aligned}
{\left[(1-\epsilon) \rho_{\mathrm{s}} v_{\mathrm{r}}\right]_{i+1 / 2, j}^{n+1}=} & C_{i+1 / 2, j}^{n}+\left(1-\epsilon_{i+1 / 2, j}^{n+1}\right) \frac{\delta t}{\delta r} \\
& \times\left(p_{i, j}^{n+1}-p_{i+1, j}^{n+1}\right)+K_{i+1 / 2, j}^{n} \\
& \times\left(u_{\mathrm{r}}-v_{\mathrm{r}}\right)_{i+1 / 2, j}^{n+1}+G_{i+1 / 2, j}^{n+1} \\
& \times \frac{\delta t}{\delta r}\left(\epsilon_{i, j}^{n+1}-\epsilon_{i+1, j}^{n+1}\right)
\end{aligned}
$$

Solid phase $z$-momentum:

$$
\begin{aligned}
{\left[(1-\epsilon) \rho_{\mathrm{s}} v_{z}\right]_{i, j+1 / 2}^{n+1}=} & D_{i, j+1 / 2}^{n}+\left(1-\epsilon_{i, j+1,2}^{n+1}\right) \frac{\delta t}{\delta z} \\
& \times\left(p_{i, j}^{n+1}-p_{i, j+1}^{n+1}\right)+K_{i, j+1 / 2}^{n} \\
& \times\left(u_{z}-v_{z}\right)_{i, j+1 / 2}^{n}+G_{i, j+1 / 2}^{n}{ }^{1}+1 \\
& \times \frac{\delta t}{\delta z}\left(\epsilon_{i, j}^{n+1}-\epsilon_{i, j+1}^{n+1}\right)
\end{aligned}
$$

where

$$
K=\delta t \beta
$$

In the finite difference representations of the momentum equations the explicit terms have been collected in:

$$
A_{i+1 / 2, j}^{n}, B_{i, j+1 / 2}^{n}, C_{i+1 / 2, j}^{n} \text { and } D_{i, j+1 / 2}^{n}
$$

and contain the finite differenced momentum convection, viscous interaction and gravity terms. Note that the interphase momentum transfer has been treated in a linear implicit fashion.

4.2.7. Discretization of the thermal energy equations. For both thermal energy equations a fully implicit discretization technique has been used. Due to the fully implicit finite differencing of these equations two algebraic relations can be obtained for each computational cell $(i, j)$ relating the fluid phase and solid phase temperatures of cell $(i, j)$ to the temperatures in the four surrounding cells:

$$
\begin{aligned}
& \left(a_{\mathrm{f}}\right)_{i-1, j}^{n+1}\left(T_{\mathrm{f}}\right)_{i=1, j}^{n+1}+\left(a_{\mathrm{f}}\right)_{i+1, j}^{n+1}\left(T_{\mathrm{f}}\right)_{i+1, j}^{n+1} \\
& +\left(a_{\mathrm{f}}\right)_{i, j-1}^{n+1}\left(T_{\mathrm{f}}\right)_{i, j-1}^{n+1}+\left(a_{\mathrm{f}}\right)_{i, j+1}^{n+\mathrm{t}}\left(T_{\mathrm{f}}\right)_{i, j+1}^{n+1} \\
& +\left(a_{\mathrm{f}}\right)_{i, j}^{n+1}\left(T_{\mathrm{f}}\right)_{i, j}^{n+1}+\left(a_{\mathrm{s}}\right)_{i, j}^{n+1}\left(T_{\mathrm{s}}\right)_{i, j}^{n+1}=\left(s_{\mathrm{f}}\right)_{i, j}^{n+1}, \\
& \left(b_{\mathrm{s}}\right)_{i-1, j}^{n+1}\left(T_{\mathrm{s}}\right)_{i-1, j}^{n+1}+\left(b_{\mathrm{s}}\right)_{i+1, j}^{n+1}\left(T_{\mathrm{s}}\right)_{i+1, j}^{n+1} \\
& +\left(b_{\mathrm{s}}\right)_{i, j-1}^{n+1}\left(T_{s}\right)_{i, j-1}^{n+1}+\left(b_{\mathrm{s}}\right)_{i, j+1}^{n+1}\left(T_{\mathrm{s}}\right)_{i, j+1}^{n+1} \\
& +\left(b_{\mathrm{s}}\right)_{i, j}^{n+1}\left(T_{\mathrm{s}}\right)_{i, j}^{n+1}+\left(b_{\mathrm{f}}\right)_{i, j}^{n+1}\left(T_{\mathrm{f}}\right)_{i, j}^{n+1}=\left(s_{\mathrm{s}}\right)_{i, j}^{n+1}
\end{aligned}
$$

In the finite difference representations simple linear interpolations have been used whenever variables are required at another mesh locations then defined according to Fig. 1:

$$
\begin{aligned}
& \epsilon_{i+1 / 2 . j}^{n+1}=\left(\epsilon_{i, j}^{n+1}+\epsilon_{i+1, j}^{n+1}\right) / 2, \\
& \epsilon_{i, j+1 / 2}^{n+1}=\left(\epsilon_{i, j}^{n+1}+\epsilon_{i, j+1}^{n+1}\right) / 2 .
\end{aligned}
$$

\subsection{Boundary conditions}

The computational mesh as shown in Fig. 2 is surrounded by a belt of fictitious or "outside" cells for the ease of treating the hydrodynamic boundary conditions. A variety of boundary conditions can be applied, by specifying the value of the cell flag $\mathrm{fl}(i, j)$ which is associated with the relevant boundary condition for cell $(i, j)$. The cell flags and the corresponding cell types are specified in Table 3 . To illustrate the incorporation of the boundary conditions for the hydrodynamic equations, the problem set-up as shown in Fig. 2 will be discussed in more detail.

$\mathbf{f}(\mathbf{i}, \mathbf{j})=\mathbf{2}$, impermeable wall cell for both phases, free-slip boundaries. These cells represent impermeable free-slip wall cells for both phases. For the scalar variables $(\epsilon, p)$ a zero gradient in the normal direction is prescribed. At an impermeable free-slip wall the normal velocity components $u_{\mathrm{r}}$ and $v_{\mathrm{r}}$ must vanish and the tangential velocity components $u_{z}$ and $v_{z}$ both have zero gradients in the normal direction.

$\mathbf{f}(\mathbf{i}, \mathbf{j})=3$, impermeable wall cell for both phases, no-slip boundaries. These cells represent impermeable no-slip wall cells for both phases. For the scalar variables $(\epsilon, p)$ a zero gradient in the normal direction is prescribed. At an impermeable no-slip wall the normal velocity components $u_{\mathrm{r}}$ and $v_{\mathrm{r}}$ and the tangential velocity components $u_{z}$ and $v_{z}$ must vanish.

$f(i, j)=5$, fluid phase influx cell, impermeable no-slip boundaries for the solid phase. Prescription of the fluid phase influx requires the specification of the normal and tangential velocity components of the 


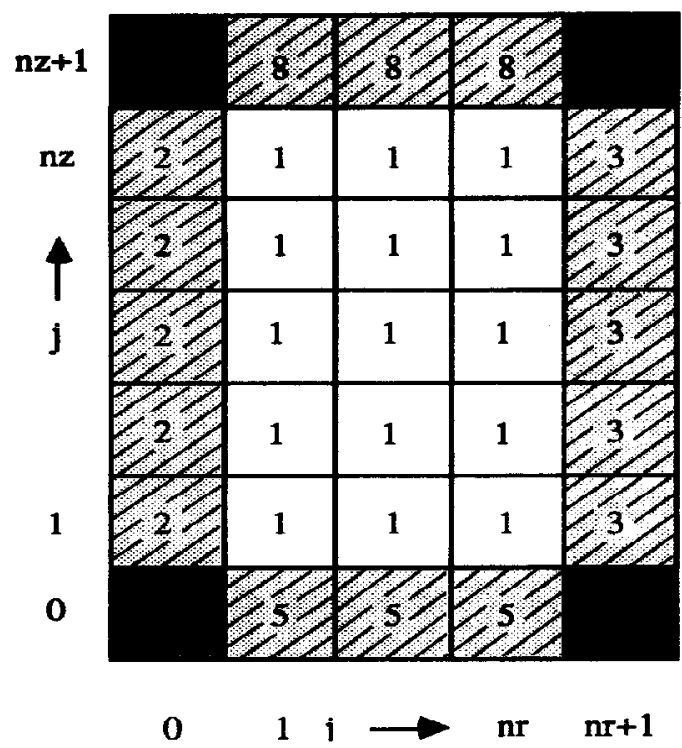




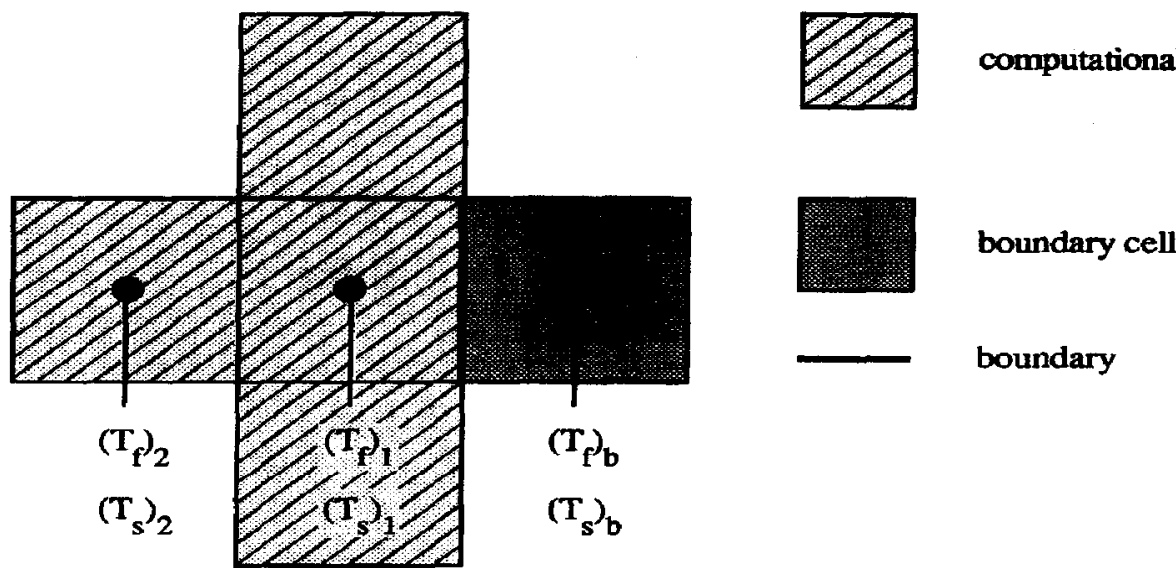

Fig. 3. The boundary temperatures $\left(T_{\mathrm{f}}\right)_{\mathrm{b}}$ and $\left(T_{\mathrm{s}}\right)_{\mathrm{b}}$ and the corresponding "internal" temperatures.

cycles, or time steps, each of duration $\delta t$. For each computational cycle the advanced or $(n+1)$ level values at time $t+\delta t$ of all the field variables have to be calculated throughout the entire computational domain. This calculation requires the old or $n$-level values at time $t$ which are known either from the previous computational cycle or from the specified initial conditions. In the present study a sequential numerical method has been adopted to obtain solutions of the full coupled set of equations and it will be discussed in this section.

4.4.1. Solution of the hydrodynamic equations. Each "hydrodynamic" computational cycle is composed of two distinct phases. In the first phase the calculation of all the explicit variables (i.e. defined at the old time level $n$ ) is performed for all interior computational cells. In the second phase the implicit part of the calculation is performed to determine the unknown porosity and pressure distributions with an iterative procedure.

The first step in the implicit phase involves the calculation of the mass residuals $\left(D_{f}\right)_{i, j}$ and $\left(D_{\mathrm{s}}\right)_{i, j}$ according to, respectively, the fluid phase continuity equation and the solid phase continuity equation, for all interior computational cells. The superscript * in these equations designates that the most recently obtained values have to be used in evaluating the expressions:

$$
\begin{aligned}
&\left(D_{\mathrm{f}}\right)_{i, j}^{*}=\left(\epsilon \rho_{\mathrm{f}}\right)_{i, j}^{*}-\left(\epsilon \rho_{\mathrm{f}}\right)_{i, j}^{n}+\frac{1}{r_{i}} \frac{\delta t}{\delta r}\left\{\left\langle r \epsilon \rho_{\mathrm{f}} u_{\mathrm{r}}\right\rangle_{i+1 / 2, j}^{*}\right. \\
&\left.-\left\langle r \epsilon \rho_{\mathrm{f}} u_{\mathrm{r}}\right\rangle_{i}^{*}{ }_{1 / 2, j}\right\}+\frac{\delta t}{\delta z}\left\{\left\langle\epsilon \rho_{\mathrm{f}} u_{z}\right\rangle_{i, j+1 / 2}^{*}\right. \\
&\left.-\left\langle\epsilon \rho_{\mathrm{f}} u_{z}\right\rangle_{i, j-1 / 2}^{*}\right\}, \\
&\left(D_{\mathrm{s}}\right)_{i, j}^{*}=\left[(1-\epsilon) \rho_{\mathrm{s}}\right]_{i, j}^{*}-\left[(1-\epsilon) \rho_{\mathrm{s}}\right]_{i, j}^{n} \\
&+\frac{1}{r_{i}} \frac{\delta t}{\delta r}\left\{\left\langle r(1-\epsilon) \rho_{\mathrm{s}} v_{\mathrm{r}}\right\rangle_{i+1 / 2, j}^{*}\right.
\end{aligned}
$$

$$
\begin{aligned}
& \left.-\left\langle r(1-\epsilon) \rho_{\mathrm{s}} v_{\mathrm{r}}\right\rangle_{i-1 / 2, j}^{*}\right\} \\
& +\frac{\delta t}{\delta z}\left\{\left\langle(1-\epsilon) \rho_{\mathrm{s}} v_{z}\right\rangle_{i, j+1 / 2}^{*}\right. \\
& \left.-\left\langle(1-\epsilon) \rho_{\mathrm{s}} v_{z}\right\rangle_{i, j-1 / 2}^{*}\right\} .
\end{aligned}
$$

If the convergence criteria:

$$
\begin{gathered}
\left(D_{\mathrm{f}}\right)_{i, j}^{*}<\operatorname{eps}_{\mathrm{f}}\left(\epsilon \rho_{\mathrm{f}}\right)_{i, j}^{*}, \\
\left(D_{\mathrm{s}}\right)_{i, j}^{*}<\operatorname{eps}_{\mathrm{s}}\left[(1-c) \rho_{\mathrm{s}}\right]_{i, j}^{*},
\end{gathered}
$$

are not satisfied simultaneously for all interior computational cells then a whole field pressure correction is calculated, satisfying for each cell $(i, j)$ :

$$
\begin{aligned}
\mathrm{J}_{i-1, j}^{n} \delta p_{i-1, j}^{\text {new }}+\mathrm{J}_{i+1, j}^{\text {new }} \delta p_{i+1, j}^{\text {new }}+\mathrm{J}_{i, j-1}^{n} \delta p_{i, j-1}^{\text {new }} \\
+\mathrm{J}_{i, j+1}^{n} \delta p_{i, j+1}^{\text {new }}+\mathrm{J}_{i, j}^{n} \delta p_{i, j}^{\text {new }}=-\left(D_{\mathrm{r}}\right)_{i, j}^{*},
\end{aligned}
$$

where $J^{n}$ represents the Jacobi matrix evaluated at the old lime level $n$ (to save computational time). The Jacobi matrix $J$ contains the derivatives of $D_{f}$ with respect to the pressure and has been obtained analytically from the momentum equations. By eliminating the pressure corrections for the boundary cells, $m$ linear equations for the $m$ unknown pressure corrections can be obtained, where $m=n r \times n z$. Solution of the corresponding banded (see Fig. 4) matrix equation with either direct or iterative methods yields the simultaneous pressure corrections for all interior computational cells. In the choice between a direct matrix solution procedure and an iterative one, the available computer memory and the number of computational cells may play a decisive role. Due to computer memory constraints, Harlow and Amsden (1974) and Rivard and Torrey (1977) used point relaxation techniques, based on the Jacobi method and the Gauss-Seidel method, respectively, to compute the pressure corrections. But to our experience 


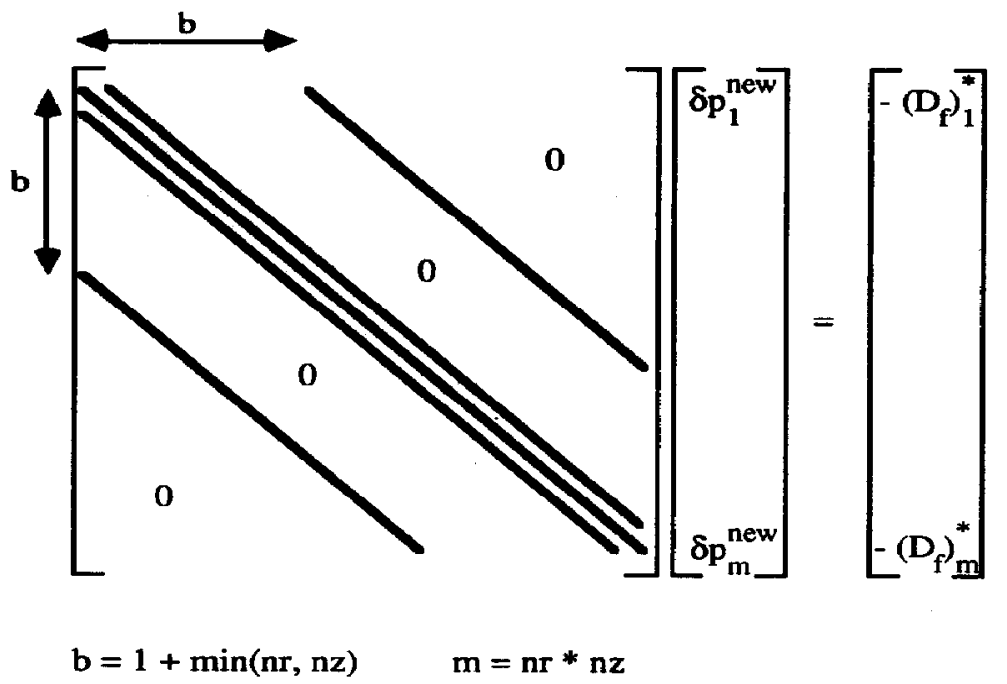

Fig. 4. Schematic representation of the matrix equation for the calculation of the pressure corrections.

these methods have poor convergence characteristics and therefore we used a whole field pressure correction technique. Stewart and Wendrotf (1984) give a qualitative explanation for the poor convergence characteristics of point relaxation methods. With the available estimates of the advanced or $(n+1)$ level pressures similar estimates of the microscopic densities, macroscopic densities, radial velocities, axial velocities and porosities can be made. If the corresponding estimates of the mass residuals, defined according to equations (9a) and (9b), do not meet the convergence criteria simultaneously for all interior computational cells, new estimates of the hydrodynamic field variables are calculated. This iterative process is terminated either by meeting the convergence criteria or by reaching the specified maximum allowable number of iterations. It may be noted that for a perfect converged solution, $\left(D_{\mathrm{f}}\right)_{i, j}=0$ and $\left(D_{\mathrm{s}}\right)_{i, j}=0$ simultaneously for all interior computational cells. When the solution of the hydrodynamic equations is completed, the solution of the thermal energy equations is performed.

4.4.2. Solution of the thermal energy equations. By eliminating the boundary temperatures according to the procedure discussed in the previous section, 2 $m$ linear equations for the $2 m$ unknown temperatures can be obtained, where $m=n r \times n z$. Solution of the corresponding banded (see Fig. 5) matrix equation with either a direct or an iterative method yields the temperatures of both phascs for all interior computational cells.

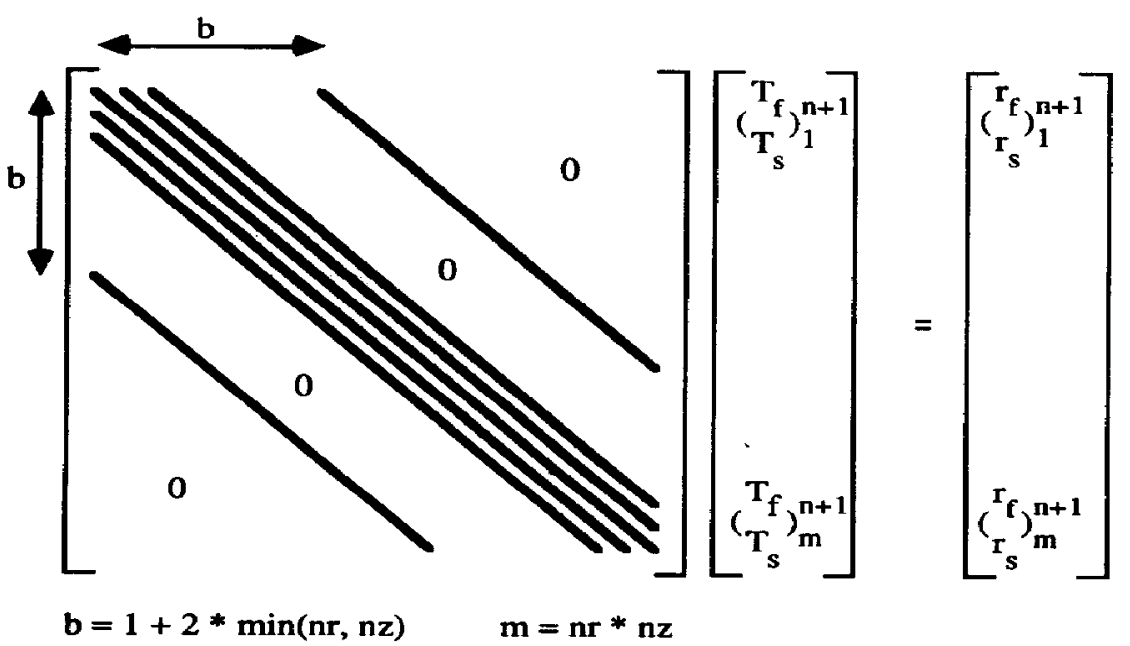

Fig. 5. Schematic representation of the matrix equation for the calculation of the temperature fields. 


\subsection{Stability considerations}

Due to the explicit treatment of the momentum convection and the viscous interaction terms the time step $\delta t$ must meet the Courant condition and the viscosity stability condition to ensure numerical stability. Automatic time step control has been incorporated in the computer code to ensure the fulfilment of these stability constraints for each computational cycle. Optionally the computer code can also be run with a fixed time step which may, of course, turn out to have been chosen too large, to avoid numerical instability.

\subsection{Computer program}

The numerical technique described in the previous sections has been embodied in an unsteady 2-D computer code written in VAX-PASCAL. Moreover, several modifications have been incorporated to allow for the presence of obstacles ("internals") in the computational domain. Internal consistency checks of the computed numerical data are automatically performed.

As an option, Lagrangian marker "particles" for both phases can be introduced in the numerical computation to allow for a visual representation of the instantaneous configuration of selected portions of the fluid phase or the solid phase. These Lagrangian marker particles provide a very convenient technique to study particle movement theoretically, a feature of obvious importance in gas particlc flows. For example, the visualization of mixing phenomena and gas flow patterns near rising bubbles can be studied theoretically with the aid of marker particles. The initial marker particle distribution and the movement of these marker particles is obtained in a similar manner to the KACHINA-code developed by Harlow and Amsden in 1974 at the Los Alamos Scientific Laboratory. These marker particles do not influence the actual numerical computation but are merely "embedded" in the fluid or the solid phases and are carried along with it. A VAX station 2000 (4 Mb internal memory), with typical mini-computer performance, has been used to generate the numerical solutions.

\section{RESULTS}

It will be evident that it is impossible to present an extensive number of simulations owing to the large number of parameters which can be varied. Furthermore, each simulation requires a huge amount of

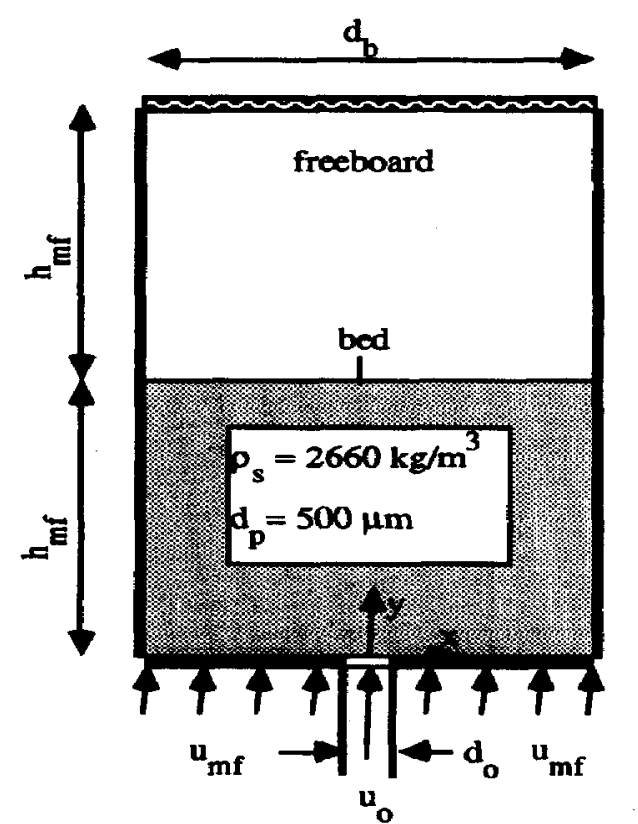

initial conditions
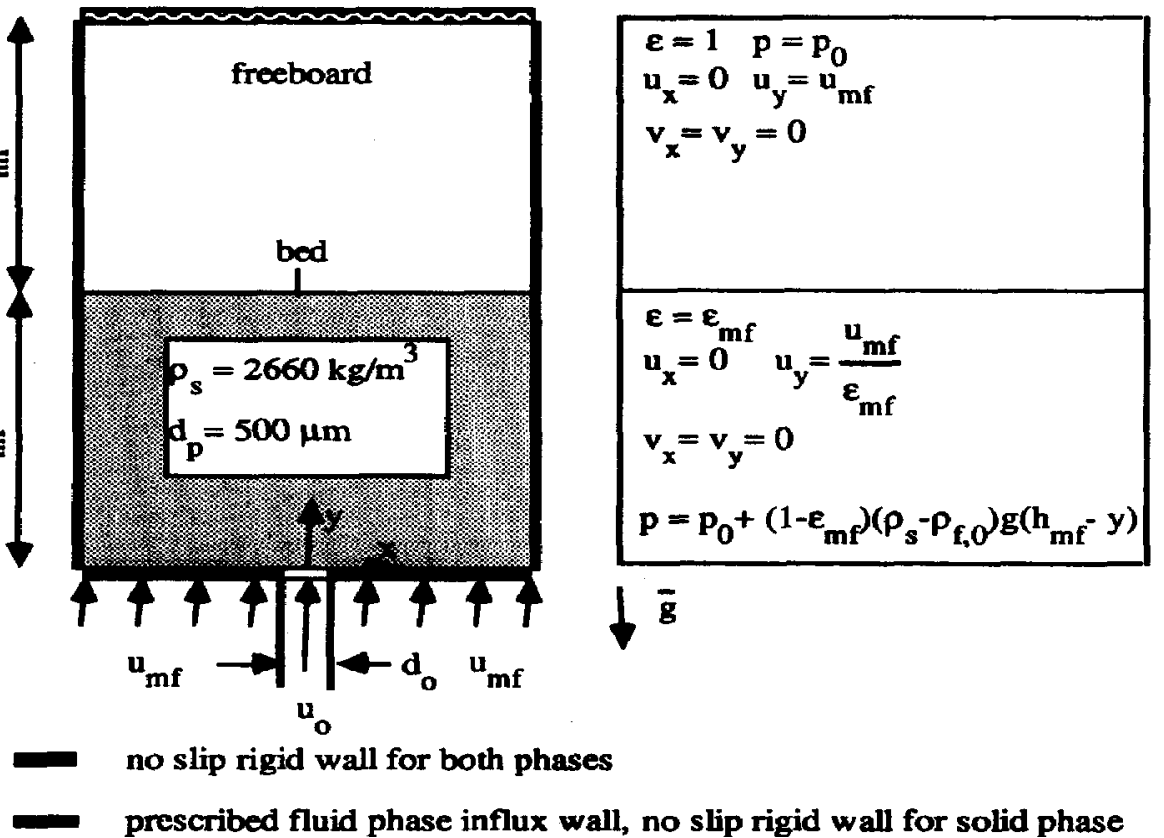

no slip rigid wall for both phases

prescribed fluid phase influx wall, no slip rigid wall for solid phase

Da continuative fluid phase outflow wall, no slip rigid wall for solid phase

Fig. 6. The initial and boundary conditions for the numerical simulation of bubble formation in a cold-flow 2-D gas-fluidized bed. 
computer time which imposes a practical constraint to keep the total computational time reasonable. As a test of the present model the phenomena associated with the formation and rise of bubbles in a 2-D cold-flow gas-fluidized bed with one central orifice have been calculated theoretically. The correct understanding and prediction of gas bubble behaviour in fluidized beds is a key issue because bubbles are responsible for many unique properties of fluidized beds. Specifically, the heat and mass transfer processes are seriously affected by the formation and propagation of gas bubbles.

Figure 6 shows the geometry of the 2-D fluidized bed considered in the numerical simulations, the corresponding numerical data are specified in Table 4. For a cold-flow gas-fluidized bed the solution of the thermal energy equations (T1-5) and (T1-6) is not required and therefore the associated initial and boundary conditions do not need further consideration. The 2-D bed is confined laterally by impermeable no-slip rigid walls for both phases, and is confined below and above by permeable walls for the fluid phase (air) and impermeable no-slip rigid walls for the solid phase. Initially the fluidizing gas, introduced at the bottom of the bed at the minimum fluidization velocity $u_{\mathrm{mr}}$, flows in the vertical $y$-direction and leaves the bed at the top. The minimum fluidization condition implies a force balance between the buoyant weight of the solid particles and the frictional forces exerted by the fluidizing gas on the solid bed particles and thus no net movement of the solid particles can occur. At zero time the gas velocity injected through the central orifice was increased instantaneously from minimum fluidization velocity $u_{\mathrm{mr}}$ to the required orifice velocity $u_{\mathrm{o}}$. As Fig. 6 shows, a freeboard of the same size as the initial bed height was provided, to allow for bed expansion due to the additional gas injection through the central orifice. To save computer time, symmetry was assumed in the simulation which can be justified on the basis of the symmetrical initial and boundary conditions.

Table 4. Data for numerical simulation

\begin{tabular}{lcc}
\hline Minimum fluidization porosity & 0.402 & \\
Minimum fuidization velocity & 0.250 & $\mathrm{~m} / \mathrm{s}$ \\
Orifice velocity & 10.00 & $\mathrm{~m} / \mathrm{s}$ \\
Fluid phase shear viscosity & $2 \times 10^{-3}$ & $\mathbf{P a . s}$ \\
Solid phase shear viscosity & 1.00 & $\mathbf{P a . s}$ \\
Particle diameter & $5.00 \times 10^{-4}$ & $\mathrm{~m}$ \\
Particle density & 2660 & $\mathbf{k g} / \mathrm{m}^{3}$ \\
Orifice diameter & $1.50 \times 10^{-2}$ & $\mathrm{~m}$ \\
Red width & 0.57 & $\mathrm{~m}$ \\
Initial bed height & 0.50 & $\mathrm{~m}$ \\
Initial freeboard pressure & 101325.0 & $\mathrm{~Pa}$ \\
Horizontal (x-) grid size & $7.50 \times 10^{-3}$ & $\mathrm{~m}$ \\
Vertical $(y-)$ grid size & $1.25 \times 10^{-2}$ & $\mathrm{~m}$ \\
Time step & $\mathbf{V a r i a b l e}$ & $\mathrm{s}$ \\
\hline
\end{tabular}

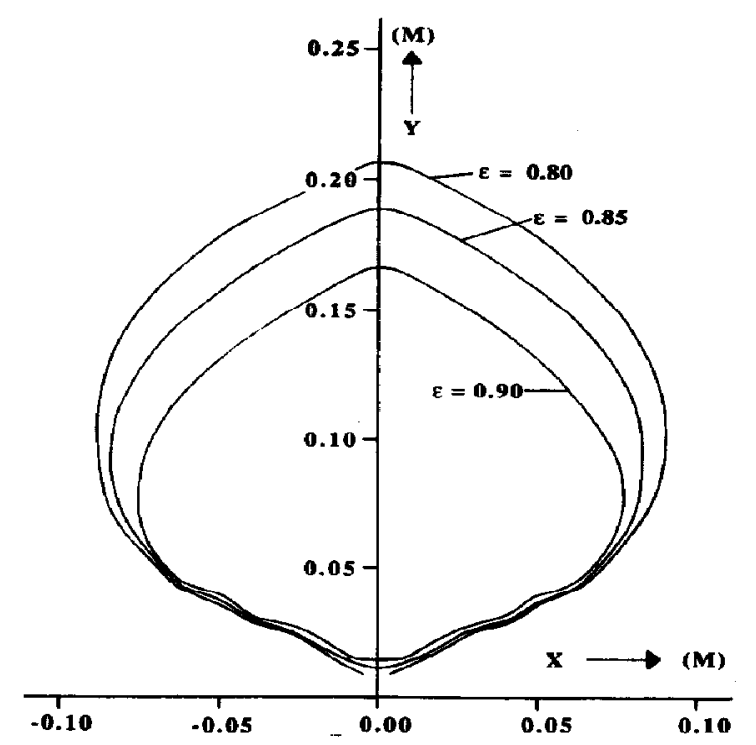

Fig. 7. Theoretically calculated porosity contours near a detached bubble at $t=0.200 \mathrm{~s}\left(u_{\mathrm{o}}=10.0 \mathrm{~m} / \mathrm{s}\right)$.

Gidaspow and Ettehadieh (1983) and Gidaspow (1986) reported results of similar computations using the inviscid model. However, they used different model parameters which precludes a quantitative comparison with their work. To study the effect of the bed rheology on predicted bubble behaviour quantitatively, a brief comparison between the results of the inviscid model and the model incorporating Newtonian behaviour in the gas and solid phase will be made here.

Figure 7 shows a number of porosity contours near the detached bubble at time $t=200 \mathrm{~s}$. It can be seen that very sharp porosity gradients exist near the bubble base, near the bubble roof these gradients are considerably weaker. This phenomenon has also been observed, although less pronounced, in experiments duplicating the computer simulation and is related to the raining of particles from the bubble roof. However, the coarseness of the computational grid $(\delta x=0.75 \mathrm{~cm}$ and $\delta y=1.25 \mathrm{~cm})$ causes some "computational smearing" of the field variables which constitutes an additional factor in explaining the (small) discrepancies between theory and experiment. A better resolution can be obtained by using a much finer grid or alternatively by applying more advanced computational schemes which possess less numerical diffusion. To determine bubble diameters from the numerically calculated porosity distributions, the bubble contour was defined as a void fraction of 0.85 . It was found that this particular choice defines the bubble boundary as a contour with very strong porosity gradients (especially near the bubble base). The equivalent bubble diameter $D_{e}$ has been obtained 
from the integration of the area $S$ for which $\epsilon>0.85$ and the definition according to:

$$
D_{\mathrm{c}}=\sqrt{\frac{4}{\pi} s},
$$

which yielded $D_{\mathrm{c}}=0.164 \mathrm{~m}$ for $t=0.200 \mathrm{~s}$. According to the two-phase theory of fluidization (Toomey and Johnstone, 1952) all gas injected in addition to the slipped gas at minimum fluidization conditions appears as bubbles and thus the predicted equivalent bubble diameter $D_{e}$ according to this simple theory becomes:

$$
D_{\mathrm{e}}=2 \sqrt{\frac{\left(u_{\mathrm{o}}-u_{\mathrm{mf}}\right) d_{\mathrm{o}} t}{\pi}} \rightarrow D_{\mathrm{c}}=0.193 \mathrm{~m}
$$

A comparison of the numerically calculated equivalent bubble diameter $D_{c}$ at $t=0.200 \mathrm{~s}$ and the prediction according to the two-phase theory of fluidization suggests that in this case approx. $28 \%$ of the injected gas, in excess of that required to just fluidize the bed ("excess gas flow") has leaked from the bubble formed into the surrounding porous emulsion phase. Experimental evidence for this phenomenon has been obtained by several workers (Nguyen and Leung, 1972; Rowe et al., 1979; Yang et al., 1984). Figure 8 allows a quantitative comparison of the theoretically calculated and experimentally determined bubble sizes as a function of time for the case without (curve a) and the case with (curve b) viscous interaction terms in the gas and solid phases. The predicted bubble growth according to the two-phase theory of fluidization [equation (13)], is included in this figure. As evident from Fig. 8, the agreement between the theoretically calculated and experimentally determined bubble diameters is very good. Furthermore, it can be concluded that the effect of the bed rheology

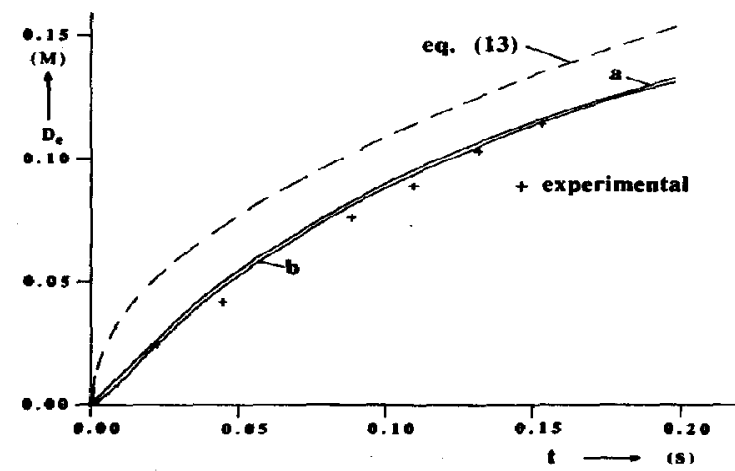

Fig. 8. Theoretically calculated and experimentally observed bubble growth at a single orifice in a 2-D gas-fluidized bed $\left(\mu_{0}=10.0 \mathrm{~m} / \mathrm{s}\right)$ in cases without (a) and with (b) viscous interaction terms in the gas and solid phases. Dashed line: two-phase theory of fluidization [equation (13)].

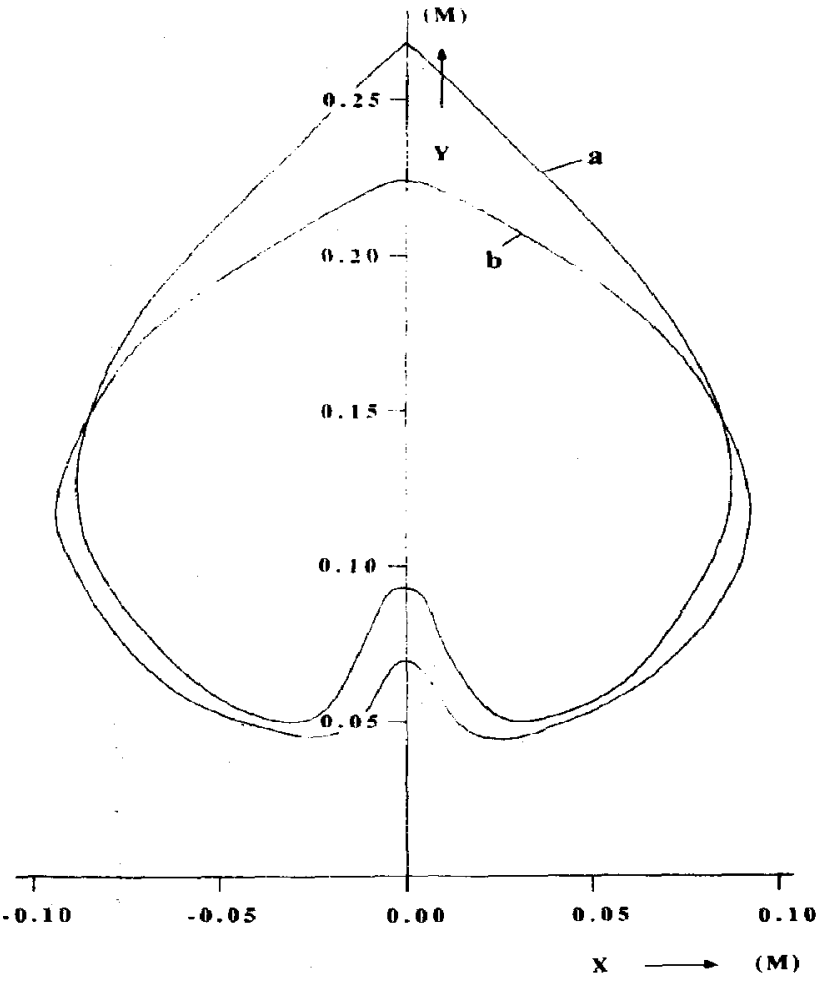

Fig. 9. Theoretically calculated bubbles in a 2-D gasfluidized bed with a central orifice $\left(u_{0}=10.0 \mathrm{~m} / \mathrm{s}\right.$ for $0 \leqslant t \leqslant 0.20 \mathrm{~s}$ and $u_{\mathrm{o}}=u_{\mathrm{mf}}=0.25 \mathrm{~m} / \mathrm{s}$ for $t>0.20 \mathrm{~s}$ ) in cases without (a) and with (b) viscous interaction terms in the gas and solid phases.

on bubble size is quite small. The two-phase theory of fluidization overestimates the experimentally observed bubble diameters during the entire process of bubble formation.

Figure 9 shows computed bubbles (bubble definition $\epsilon>0.85$ ) for the case without (a) and the case with (b) viscous interaction terms in the gas and solid phases; the corresponding bubble parameters (i.e. size and shape) are listed in Table 5. Here the duration of secondary (i.e. in excess of the minimum fluidization velocity) gas injection through the central orifice was limited to $0.20 \mathrm{~s}$. Contrary to bubble size, bubble shape appears to be sensitive to the bed rheology. Especially near the upper ("bubble nose") and lower ("bubble wake") stagnation points the inviscid model predicts a shape which differs from the model which

$\begin{aligned} & \text { Table 5. Equivalent bubble diameters and } \\
& \text { bubble shape factors } \sigma=D_{\mathrm{v}} / D_{\mathrm{h}} \text { without (a) and } \\
& \text { with (b) viscous interaction terms in gas and } \\
& \text { solid phases }\end{aligned}$
\begin{tabular}{cccc}
\hline Case & $t(\mathrm{~s})$ & $D_{\mathrm{c}}(\mathrm{m})$ & $\sigma=D_{\mathrm{v}} / D_{\mathrm{h}}$ \\
\hline a & 0.248 & 0.182 & 1.24 \\
b & 0.242 & 0.175 & 0.97 \\
\hline
\end{tabular}



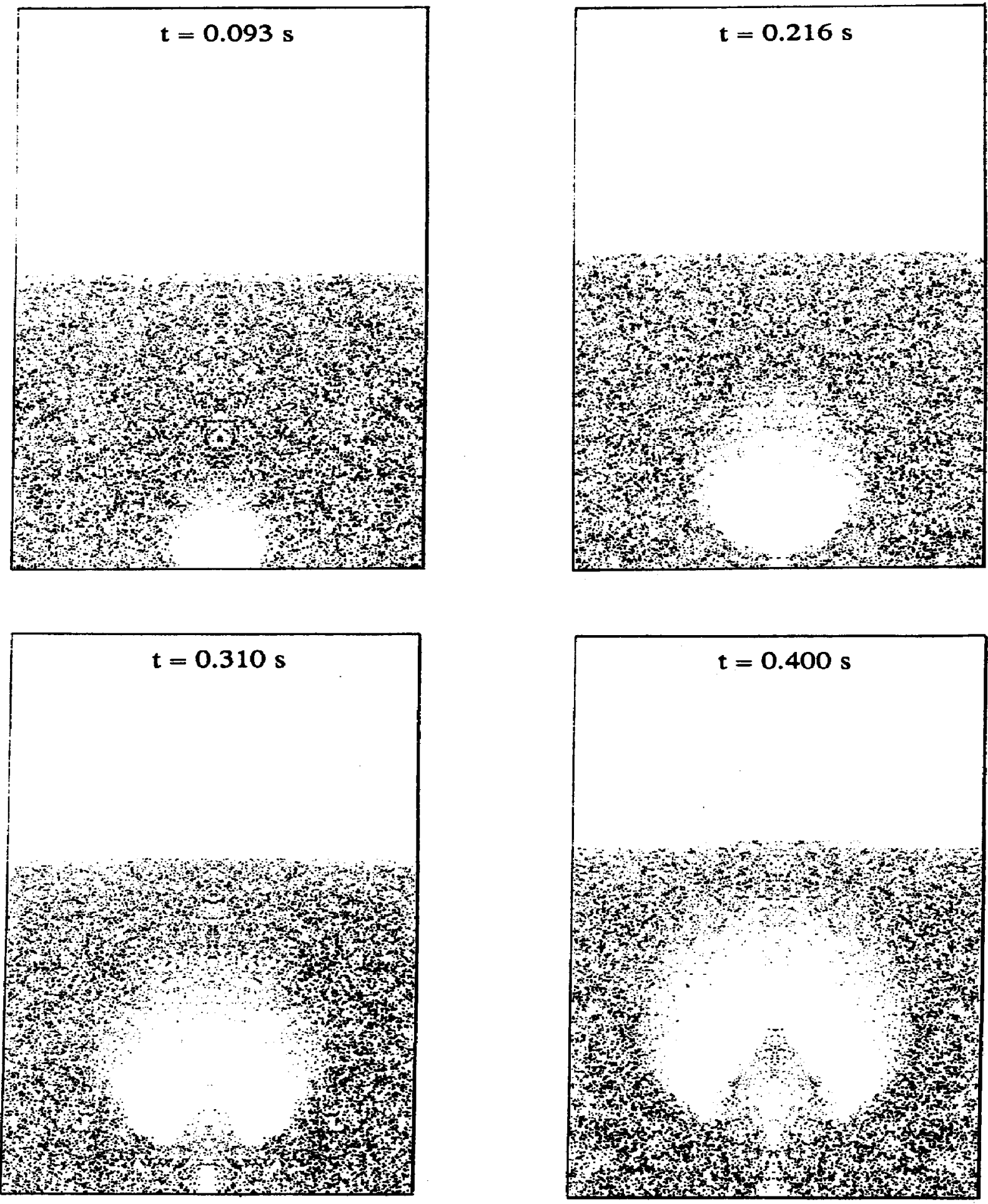

Fig. 10a. Simulated bubble formation and bubble propagation in a 2-D gas-fluidized bed with a central orifice $\left(u_{0}=10.0 \mathrm{~m} / \mathrm{s}\right)$. 

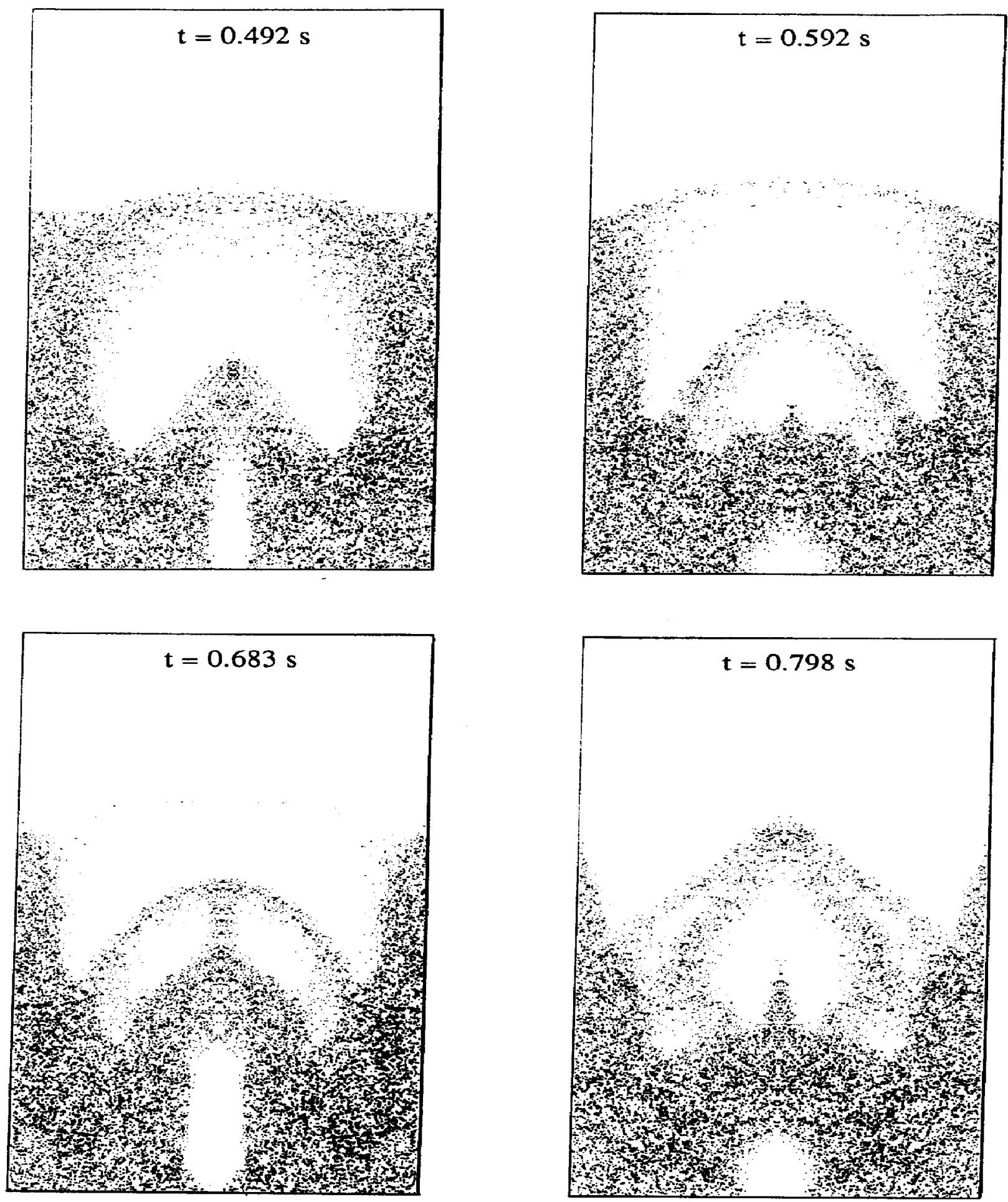

Fig. 10b. See Fig. 10a. 
$\mathrm{t}=0.360 \mathrm{~s}$

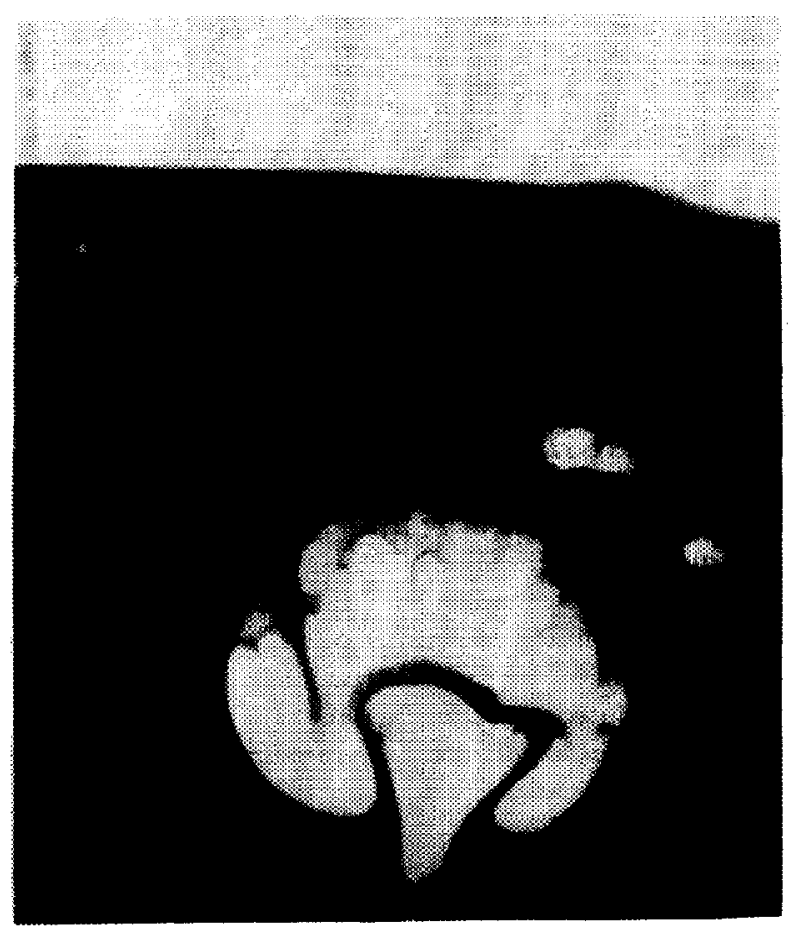

$t=0.560 \mathrm{~s}$

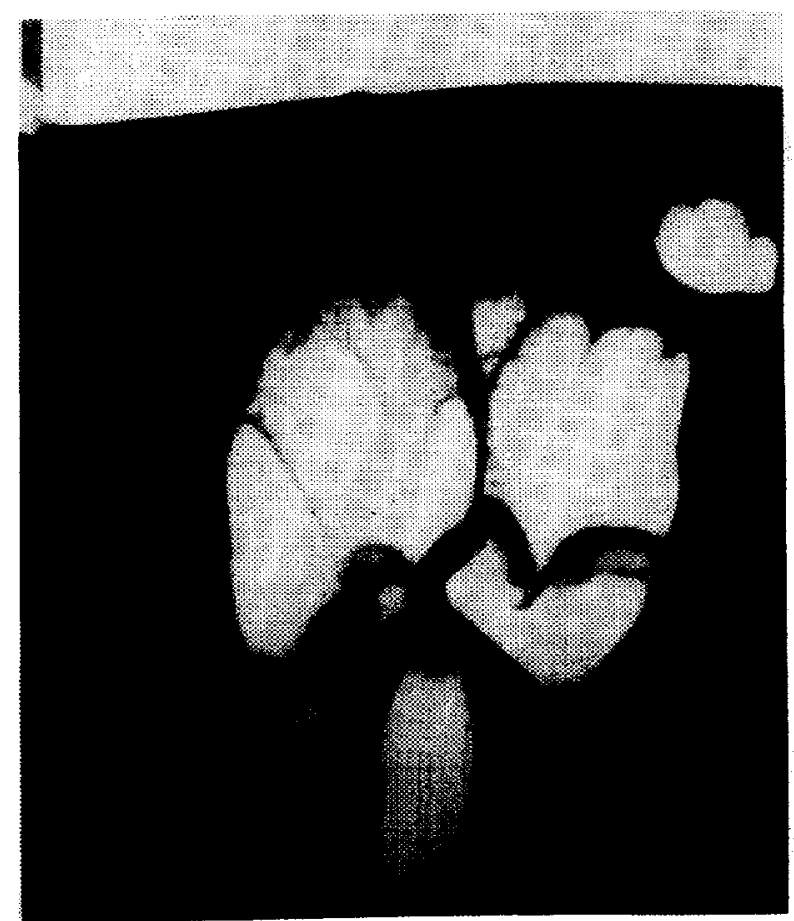

$\mathrm{t}=0.460 \mathrm{~s}$

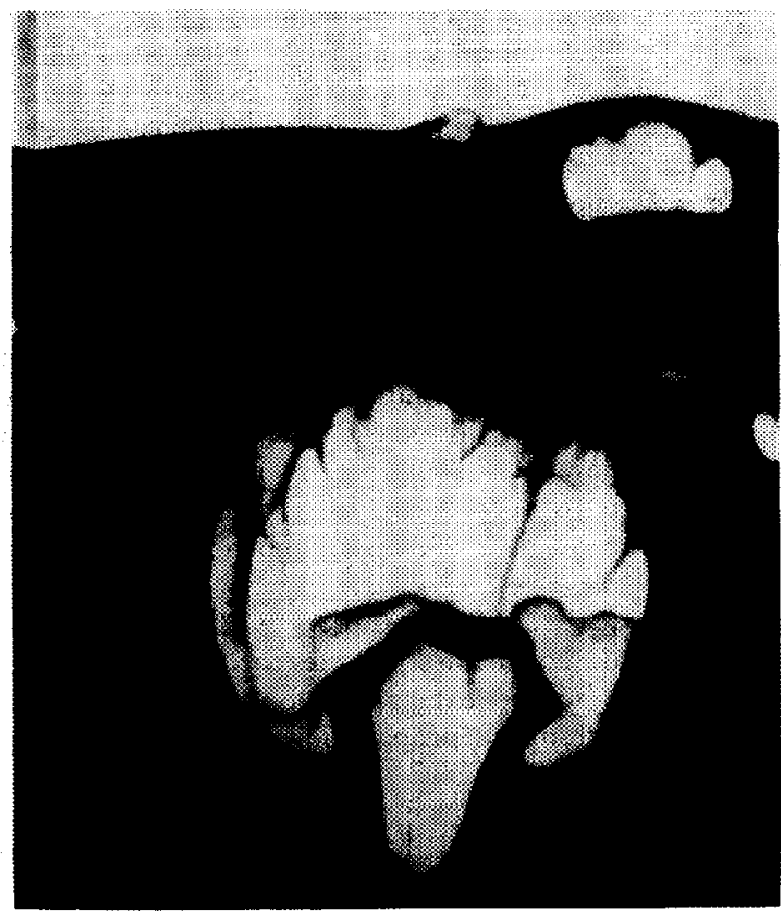

$t=0.660 \mathrm{~s}$

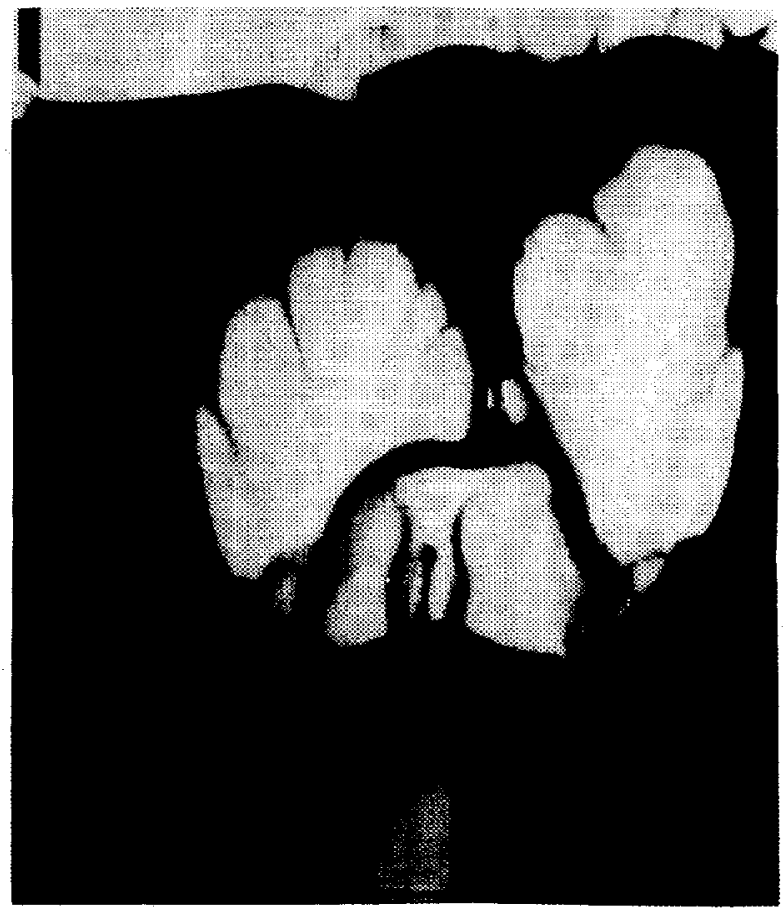

Fig. 11. Bubble formation and bubble propagation in a 2-D gas-flu. lized bed with a central orifice $\left(u_{0}=10.0 \mathrm{~m} / \mathrm{s}\right)$. 
incorporates Newtonian behaviour in the gas and solid phases. As is evident from Fig. 9 and Table 5, the inviscid model predicts an elongated bubble ( $\sigma=D_{v} / D_{\mathrm{h}}=1.24$ ) whereas the model with Newtonian behaviour of the gas and solid phases predicts, as experimentally observed, a nearly circular bubble $\left(\sigma=D_{\mathrm{v}} / D_{\mathrm{h}}=0.97\right)$.

In order to obtain a visual representation of the computed results, the calculated instantaneous solidity distributions have been converted into dot plots by a laser printer. The dots are distributed randomly throughout each computational cell in such a manner that the resulting dot density of cell $(i, j)$ corresponds to the computed instantaneous solidity $[1-\epsilon(i, j)]$ of cell $(i, j)$. In accordance with the adopted bubble definition no dots are distributed in computational cells whenever $\epsilon(i, j)>0.85$. Figures $10 a$ and $b$ show a sequence of such dot plots which illustrate the propagation of the first bubbles through the fluidized bed. The theoretical calculation correctly predicts the formation and propagation of a relatively large
Table 6. Experimental and theoretical equivalent bubble diameters

\begin{tabular}{ccc} 
& $\begin{array}{c}\text { Experimenta1 } \\
(t=0.300 \mathrm{~s})\end{array}$ & $\begin{array}{c}\text { Theoretical } \\
(t=0.310 \mathrm{~s})\end{array}$ \\
\hline$D_{\mathrm{h}}$ & $0.223 \mathrm{~m}$ & $0.233 \mathrm{~m}$ \\
$D_{\mathrm{s}}$ & $0.218 \mathrm{~m}$ & $0.173 \mathrm{~m}$ \\
$D_{c}$ & $0.225 \mathrm{~m}$ & $0.193 \mathrm{~m}$ \\
\hline
\end{tabular}

start-up bubble and subsequent evolution of small elongated bubbles at the jet mouth. From visual observations and triggered photographs a very similar picture emerges as evident from the photographs shown in Fig. 11. However, the agreement between theory and experiment is not perfect which can be expected at this stage of theoretical development. For example, the theoretical model assumes Newtonian behaviour of the dense phase which must be regarded as a first approximation of the true rheological behaviour of fluidized suspensions. Furthermore, the discrepancies between theory and experiment can be attributed, to some extent, to asymmetries present in the experiment. Symmetry about the

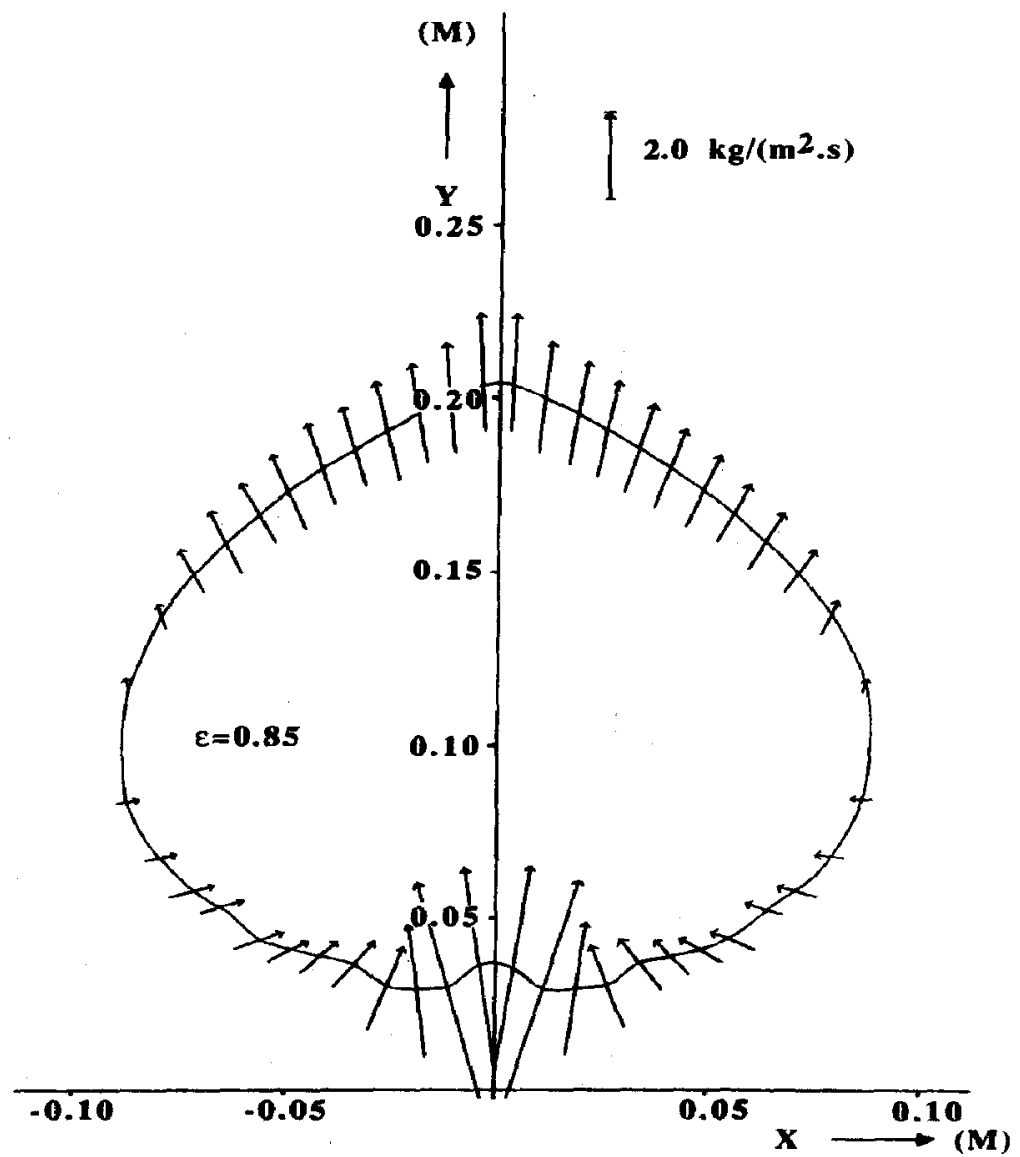

Fig. 12. Computed mass flux of the gas phase at the bubble boundary $(\epsilon=0.85)$ at $t=0.216 \mathrm{~s}$ $\left(u_{0}=10.0 \mathrm{~m} / \mathrm{s}\right)$ 
vertical line passing through the bed centre has been assumed in the computer simulation duplicating the experiment.

A comparison between the experimental (at $t=0.300 \mathrm{~s}$ ) and theoretical (at $t=0.310 \mathrm{~s}$ ) bubble diameters is presented in Table 6 . The close agreement between the experimental data and the predictions from the hydrodynamic model is remarkable especially when it is borne in mind that the model does not contain adjustable parameters. Figure 12 shows the computed mass flux of the gas phase at the bubble boundary (defined as a void fraction of $\mathbf{0 . 8 5}$ ) at $t=0.216 \mathrm{~s}$. From this figure it can be seen that the bubble acts as a short circuit for the gas flow through the fluidized bed. At the bubble base gas flows into the bubble, whereas at the bubble roof gas flows into

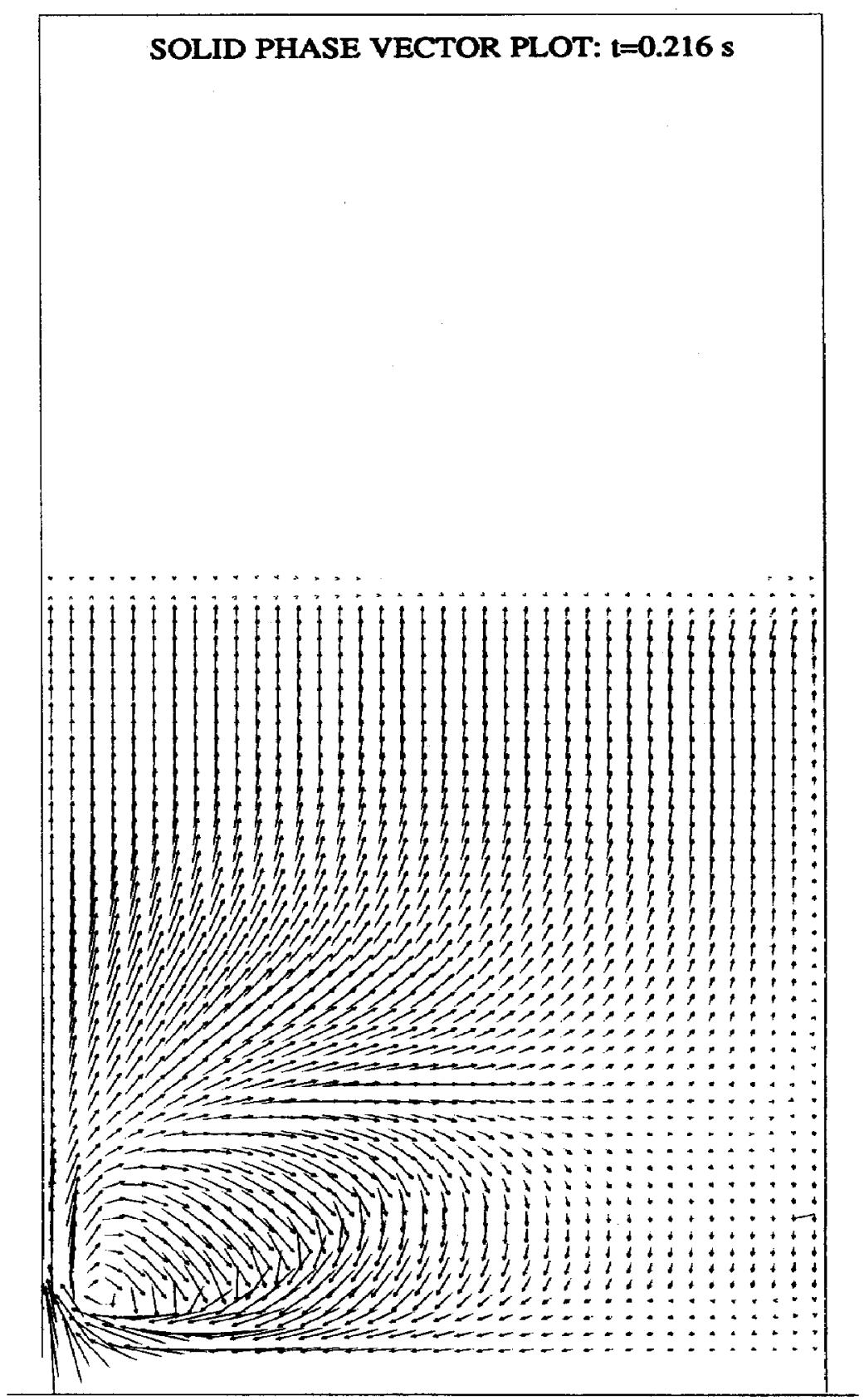

Fig. 13a. Solid phase vector plot at $t=0.216 \mathrm{~s}$ 
the emulsion phase. Although bubble detachment has already occurred at time $\iota=0.188 \mathrm{~s}$ (corresponding equivalent bubble diameter $D_{t}=0.160 \mathrm{~m}$ ), substantial inflow of the gas injected through the orifice still takes place at $t=0.216 \mathrm{~s}$, as evident from inspection of Fig. 12.

Figures 13a and $b$ show two vector plots of the solid phase velocity at, respectively, $t=0.216$ and $t=0.310 \mathrm{~s}$. From these vector plots it can be seen that a very vigorous solid motion exists in the wake of the rising bubble. Furthermore, it can be seen that the rising bubble induces an overall circulation of bed material. In accordance with visual observations from the 2-D fluidized bed, the theoretical calculation predicts an upflow of bed material along the bed centre line and downflow of bed material near the

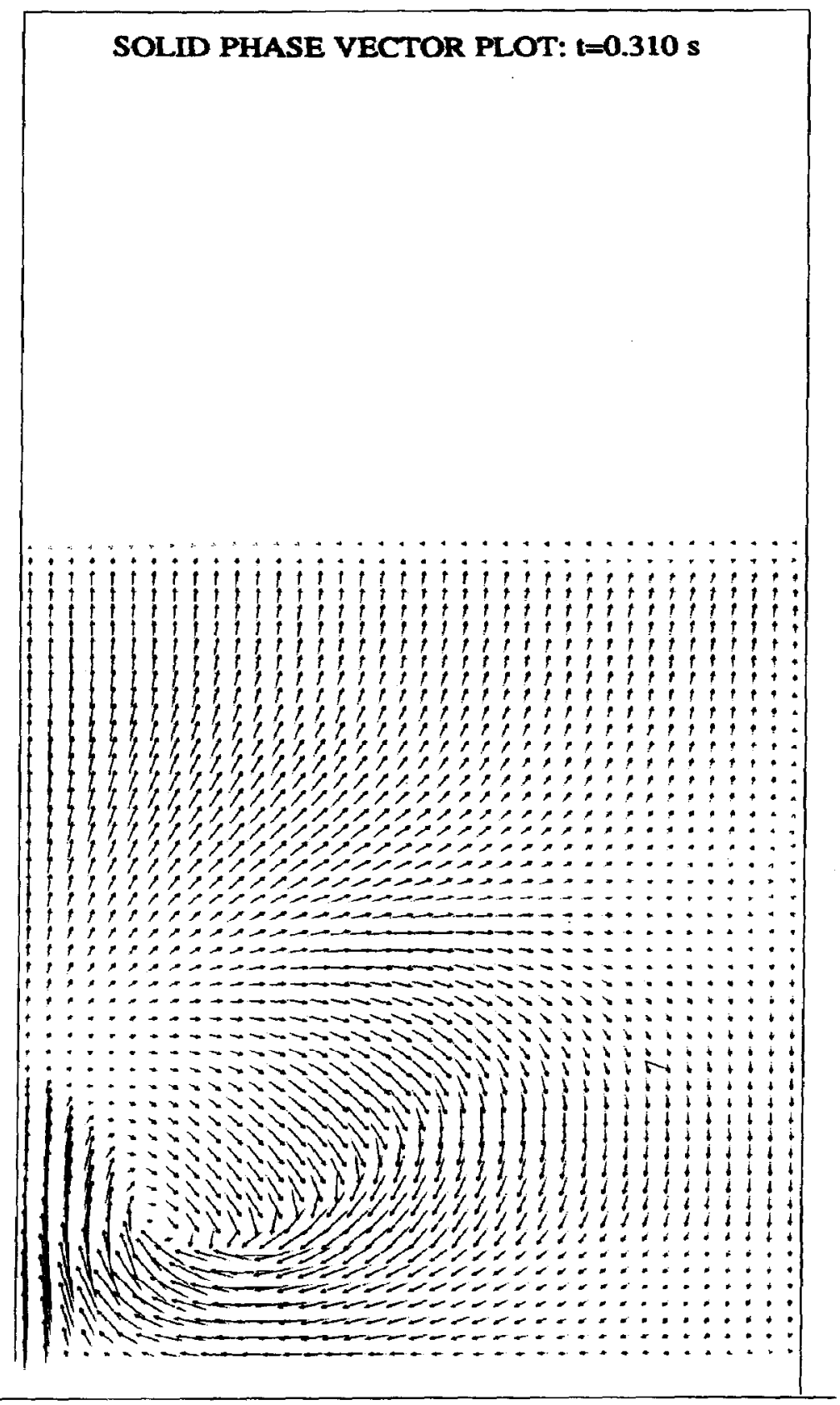

Fig. 13b. Solid phase vector plot at $t=0.310 \mathrm{~s}$. 


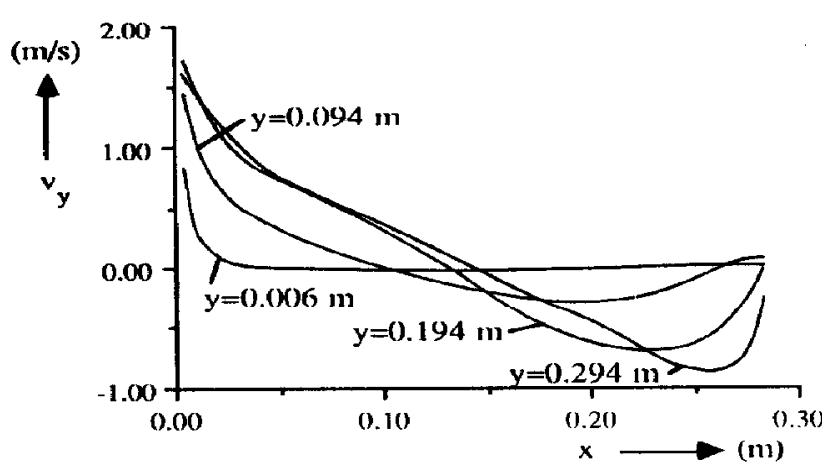

Fig. 14. Theoretically calculated time-averaged axial solids velocity $v_{y}$ as a function of the distance $x$ from the bed centre line at various heights $y$ above the gas distributor $\left(u_{\circ}=10.0 \mathrm{~m} / \mathrm{s}\right)$.

side walls of the bed. This behaviour is also evident from Fig. 14 which shows the theoretically calculated time-averaged axial solids velocity $v_{y}$ as a function of the distance to the bed centre line at various heights $y$ above the gas distributor. To keep the required computer time reasonable, time-averaging was performed over $1 \mathrm{~s}$ of real time. The velocity profiles shown in Fig. 14, pass through a minimum which becomes more pronounced with increasing distance above the gas distributor plate. Furthermore, the region with the most dominant downflow of the solid particles shifts towards the side walls of the bed with increasing distance from the gas distributor plate. From our visual observations a qualitatively similar picture emerged.

\section{CONCLUSIONS}

A first principles hydrodynamic model for a gasfluidized bed based on the so-called two fluid model (TFM) has been developed. The TFM mass, momentum and thermal energy equations have been solved numerically by a finite difference technique on a minicomputer. A computer model has been developed which calculates the porosity, the pressure, the fluidum phase temperature, the solid phase temperature and the velocity fields of both phases in 2-D Cartesian or axisymmetrical cylindrical coordinates.

The observed bubble behaviour in a 2-D gasfluidized bed with a central orifice was predicted satisfactorily by our hydrodynamic model. Our preliminary calculations indicate that the sensitivity of computed bubble size with respect to the bed rheology (i.e. the solid phase viscosity) is quite small. However the bubble shape appears to be much more sensitive to the bed rheology, especially near the upper and lower stagnation points. None of the model parameter values were fitted; all of them have been obtained directly from available theory or wellestablished empiricism. Unlike the two-phase model of fluidization, no specific assumptions concerning the gas flow distribution between the "bubble phase" and "emulsion phase" have to be made in the present model. The most powerful property of the advanced hydrodynamic model, specially in combination with visualization techniques, is the $a$ priori prediction of observable macro-scale phenomena such as the occurrence of gas bubbles.

In its present state the model does not correctly display all the details associated with the propagation of bubbles in gas-fluidized beds. The further development of the model, both from a physical (bed rheology) and mathematical (finite difference approximations) point of view seems highly desirable.

Acknowledgement-This investigation was supported by VEG-Gasinstituut B. V. of the Netherlands, Central Technical Institute of the Dutch gas supply companies.

\section{NOMENCLATURE}

$A=$ Defined in equation (T2-6e)

$B=$ Defined in equation (T2-6d)

$C_{\mathrm{d}}=$ Drag coefficient

$C_{\mathrm{p}}=$ Heat capacity, $\mathrm{J} /(\mathrm{kg} \cdot \mathrm{K})$

$D_{\mathrm{f}}=$ Mass residual according to fluid phase continuity equation, $\mathrm{kg} /\left(\mathrm{m}^{3}\right)$

$D_{\mathrm{s}}=$ Mass residual according to solid phase continuity equation, $\mathrm{kg} /\left(\mathrm{m}^{3}\right)$

$D_{\mathrm{e}}=$ Equivalent bubble diameter, $\mathrm{m}$

$D_{\mathrm{h}}=$ Horizontal bubble diameter, $\mathrm{m}$

$D_{\mathrm{v}}=$ Vertical bubble diameter, $\mathrm{m}$

$d_{\mathrm{b}}=$ Bed diameter, $\mathrm{m}$

$d_{\mathrm{o}}=$ Orifice diameter, $\mathbf{m}$

$d_{\mathrm{p}}=$ Particle diameter, $\mathrm{m}$

$E=$ Unit tensor

eps $=$ Relative precision for pressure iteration

$f(\epsilon)=$ Interaction function defined in equation (T2-2c)

$G(\epsilon)=$ Particle-particle interaction modulus, $\mathbf{P a}$

$g=$ Gravitational force per unit mass, $\mathrm{m} / \mathrm{s}^{2}$

$h_{\mathrm{mf}}=$ Bed height at minimum fluidization conditions, $m$

$I=$ Internal energy, $\mathrm{J} / \mathrm{kg}$

$i=$ Lateral cell index

$j=$ Vertical cell index

$\dot{M}=$ Molecular weight, $\mathrm{kg} / \mathbf{k m o l}$

$\mathrm{Nu} u_{p}=$ Particle Nusselt number

$n r=$ Number of computational cells in radial direction

$n z=$ Number of computational cells in axial direction

$\mathrm{Pr}=$ Prandtl number

$p=$ Pressure, $\mathbf{P a}$

$R=$ Gas constant, $\mathrm{J} /(\mathrm{kmol} \cdot \mathbf{K})$

$\mathbf{R e}_{\mathrm{p}}=$ Particle Reynolds number

$r=r$-Coordinate, $\mathrm{m}$

$S=$ Bubble area, $\mathrm{m}^{2}$

$T=$ Temperature, $\mathrm{K}$

$t=$ Time, $s$

$\bar{u}=$ Fluid phase velocity, $\mathrm{m} / \mathrm{s}$

$u_{\mathrm{mf}}=$ Superficial injection velocity through orifice, $\mathrm{m} / \mathrm{s}$

$\bar{v}=$ Solid phase velocity, $\mathrm{m} / \mathrm{s}$

$x=x$-Coordinate, $\mathrm{m}$

$y=y$-Coordinate, $\mathrm{m}$

$z=z$-Coordinate, $m$ 
Greek letters

$\alpha=$ Volumetric interphase heat transfer coefficient, $\mathbf{W} /\left(\mathrm{m}^{3} \cdot \mathbf{K}\right)$

$\alpha_{\mathrm{p}}=$ Fluid-particle heat transfer coefficient, $W /\left(\mathbf{m}^{2} \cdot \mathbf{K}\right)$

$\beta=$ Volumetric interphase momentum transfer coefficient, $\mathrm{kg} /\left(\mathrm{m}^{2} \cdot \mathrm{s}\right)$

$\delta r=$ Radial computational cell dimension, $m$

$\delta i=$ Time step, $\mathrm{s}$

$\delta x=$ Horizontal computational cell dimension, $m$

$\delta y=$ Vertical computational cell dimension, $m$

$\delta z=$ Axial computational cell dimension, $m$

$\epsilon=$ Fluid phase volume fraction

$\epsilon_{\mathrm{mf}}=$ Fluid phase volume fraction at minimum fluidization conditions

$\phi_{\mathrm{s}}=$ Sphericity

$\Gamma=$ Defined in equation $(T 2-6 c)$

$\kappa=$ Thermal conductivity, $\mathrm{W} /(\mathrm{m} \cdot \mathrm{K})$

$\mu=$ Shear viseosity, $\mathrm{kg} /(\mathrm{m} \cdot \mathrm{s})$

$\rho=$ Density, $\mathrm{kg} / \mathrm{m}^{3}$

$\sigma=$ Bubble shape factor, $\sigma=D_{\mathrm{v}} / D_{\mathrm{h}}$

$\Theta=$ Mass, momentum, energy density, $\mathrm{kg} / \mathrm{m}^{3}, \mathrm{~kg} /\left(\mathrm{m}^{2} \cdot \mathrm{s}\right), \mathrm{I} / \mathrm{m}^{3}$

$\omega=$ Defined in equation (T2-61)

\section{Subscripts}

$\mathrm{f}=$ Fluid phase

$\mathrm{mf}=$ Minimum fluidization conditions

$0=$ Microscopic property

$\mathrm{p}=$ particle

$r=r$-Direction

$\mathrm{s}=$ Solid phase

$x=x$-Direction

$y=y$-Direction

$z=z$-Direction

$\mathbf{0}=$ Freeboard conditions

\section{Superscripts}

$n=$ Time level

$\mathbf{T}=$ Transpose

* = Most recently obtained values in pressure iteration

\section{Operators}

$\nabla=$ Gradient

$\nabla \cdot=$ Divergence

\section{REFERENCES}

Anderson T. B. and R. Jackson, Ind. Engng Chem. Fundam. 6, 527 (1967).
Ettehadieh B., D. Gidaspow and R. W. Lyczkowski, AIChE Jl 30, 529 (1986).

Gabor J. D., The Chem. Engr. J. 4, 118 (1972).

Gidaspow D., Appl. Mech. Rev. 39, 1 (1986)

Gidaspow D. and B. Ettehadieh B., Ind. Engng Chem. Fundam. 22, 193 (1983).

Harlow F. H. and A. A. Amsden, J. Comput. Phys. 8, 197 (1971).

Harlow F. H. and A. A. Amsden, Kachina: an Eulerian computer program for multifield fluid flows. Los Alamos, Report (1974).

Henline W. D., H. H. Klein, M. F. Scharff and B. Srinivas, Final Report on Computer Modelling of the U-Gas Reactor DOE, DE-ACO2-77ET13406, JAYYCOR (1981).

Ishii M., Thermo-Fluid Dynamic Theory of Two Phase Flow. Eyrolles, Paris (1975).

Klein H. H. and M. F. Scharff, ASME Paper 82-FE-6 (1982).

Nguyen X. T, and L. S. Leung, Chem. Engng Sci. 27, 1748 (1972).

Pritchett J. W., T. R. Blake and S. K. Garg, AIChE Symp. Ser. 74, 134 (1978).

Rivard W. C. and M. D. Torrey, K-FIX: a computer program for transient two-dimensional, two-fluid flow, Los Alamos, Report LA-NUREG-6623 (1977).

Rivard W. C. and M. D. Torrey, THREED: an extension of the K-FIX Code for Three Dimensions. Los Alamos, Report I.A-NIJREG-6623 (1979).

Rowe P. N., H. J. MacGillivray and D. J. Cheesman, Trans. Instn. Chem. Engrs 57, 194 (1979).

Rudinger G. and A. Chang, Phys. Fluids 7, 1747 (1964).

Scharff M. F., R. K-C. Chan, M. J. Chiou, D. E. Dietrich, D. D. Dion, H. H. Klein, D. N. Laird, H. R. Levine, C. A. Meister and B. Srinivas, Computer Madelling of Mixing and Aggiomeration in Coal Conversion Reactors, Vols I \& II. DOE/ET/10329-1211, JAYCOR (1982).

Schneyer G. P., E. W. Peterson, P. J. Chen, D. H. Brownell and T. R. Blake, Computer modelling of coal gasification reactors. Final Report for June 1975-1980 DOE/ET/10247. Systems. Science and Software (1981).

Syamlal M. and D. Gidaspow, $A / C h E H I 31,127$ (1985).

Stewart H. B. and B. Wendroff, J. Comput. Phys. 56, 363 (1984).

Toomey R. D. and H. F. Johnstone, Chem. Engng Prog. 48, 220 (1952)

Yang W.-C., D. Revay, R. G. Anderson, E. J. Chelen, D. L. Keairns and D. C. Cicero, In Fluidization (Edited by $D$. Kunii and R. Toei), p. 77. Engineering Foundation, distributed by AIChE (1984). 